

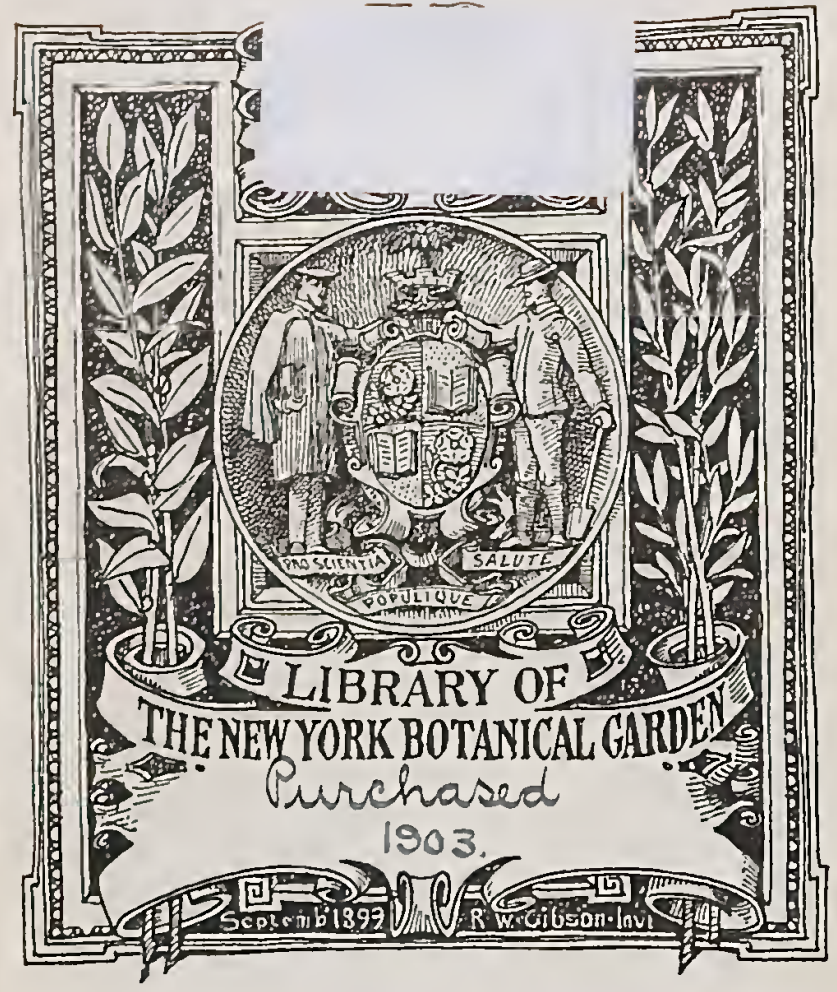





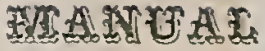

DEE

\section{JARDTHERO GUBANO}

Tratado completo do

floricultura con todos los

secretos para sembrar, plantar, inger-

tar, abonar y podar Jas plantas

de fiores, su riego, enfermedades y enemigos.

I:3

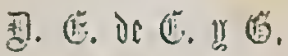

De venta Calzada de Galiano núm, 95; ikil)(

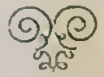

\section{Jaca3atra.}

Imprenta Militar do la Viuda de Soler y Compo" 1872. 


$$
\begin{aligned}
& 58 \\
& 406.93 \\
& . C 9 \\
& C 65
\end{aligned}
$$




\section{LAS FLORES.}

El cullivo de las flores, es la oeupreion mas agradable $y$ la que recompensa con purisimos placeres y goces cltrabajo que se emiplea en ellas.

Remover la lierra, espetritr la semilla de sembrarla. de esiacas, regarlus, verlu germinar, creecr las plantas Rareeer y finetificar, son mulaciones que deleiun nues. tros seillidos y precuben del fustidlio inseparable de la
ociosidad.

iCuanto se goza al contempler un jardin a la salida del sol, que cires tan paros se respiran en sus coritornos!

iCuanta belleza, cumna fragancia y cuantos miste. rios se encicrran en cada flor!

La mano de Dios, confió al Reino Tegetal, la importantisima mision de purificar el aire que respiramos, le tió órganos pura que moridos por los rayos del Sol, recogiera dle la almóstera las suścaneias venenosas y devolvicra un gitus que es el que manticne la villa de lorlo el Ficino animul.

Al la risia de une fír, rum la mas scneilla y agresie el mas desereido se convievle ch ereyente.

Si no hubiera sobie la licma, otrus muehas pruevas de la existencia, bondad y subiduria de Dios, si no pudiéramos contcmplur cl firmumento, las flores solus bastarian para reconoecrle y admirarle. 


\section{$-4-$ \\ SECCION PRIMERA.}

Contiene un tratado de jardineria y floricultura Cubana, con los secretos parn sembrar, plantar, ingertar y cultivar las plantas ile flores y yerbas aromáticas y medicinales, con el metodo de preparar los terrenos para cala especie, el buen mantillo para abonos, las enfermedades de las plantas y sus enemigos dic. \&ec.

\section{IMPORTANCIA DEL ABONO.}

Para obtener hermosas florcs de las plantas, debe abonarse el terreno en que se siembra con mantillo, este so prepara fácilmente del modo siguiente; se abro en el suclu un hoyo de dos varas en cuadro por dos varas tambien de profundidad, en el cual se vierten hojas de árboles y jerbas, estiercol, orines, cenizas, y demas basuras y para que mas pronto se convierta en tierra se ricga con frecuencia y se tapa con tablas para que los jugos uutritivos y gascs couvcnientes á la vegctacion, se reconcentren y se fijen cn este mantillo. Si la aglonjeracion de estas basuras se hiciera sobre el terreno sin depositarse en la cscaracion que so ha esplicado, la tierra 6 mantillo que se obtieno de este modo aunque bueno para los abones, no ticne la energía que el preparado bajo las reglas que primero se esplicaron. 
Euando se emplea esie mantillo, para abonar el torreno en donde se halla plantado el árbol que se quiere vigorizar, para que produzce muchas y hermosas flores ó abundantes $y$ mejores frutas; basta escarar al rededor del tronco la tierra que cuhre sus raices, estender una capa del mantillo $y$ cubrirlo cou la tierra que se estrajo. Cuando se quiere preparar una buena tierra para siembra, supongamos una maceta, se hace en la proporcion siguiente-tierra de la comun 3 partes, Mantillo__ 1 parte. Si la ticrra comun que se emplea es arcillosa, se le echa uu poco de areua $y$ seaumcuta hastia un tercio de mintillo. Todo se revuelve bieu paraque las partes formen mit masa homagenea. El yeso on polro es tambien un buon fertiliziute para los cerlejos.

Frauklin lo demostró hasta la evidencia á sus compatriotas de un modo muy iugenioso. Hizo sombrar un camplo de trigo, en el telreno habia regado seso en polro de tal iuodo.que formara letras du gritudes dim.rusiones que unidas dijera-PONER DEL YESOcuaudo hubo evecirlo el trigo, se adrirtió, que tudo el que nació en la parte abonada cou el jeso creció uas, J las espigis, eran majores, de modo que su veia en griu relicve el letrero.

Franklin conroeó á todus los do la comarca y los lleจó al campo sembrado de trigo; situados eu un lugar elevado y it distancia conrcnieute todos leyeron con asombro el elocuento y persuasivo letrero- $P O D E R$ DEL YESO-

Las plautas para su lozania necesitan del riego, do la luz del Sol y dol aire, el Sol alemísilel lumínieo suministra ol beuéfico calor iudispensablo como los demas agentes para la vida de las plantas $y$ de los animales. 
Todos habrán tenido ocasion de notar, que las plantas colocadas en lugares oscuros, palidecen sus hojas y renueros, no siendu vira la citusa que la fialta de luz:

\section{I) LOS ROSALES. \\ Rosal de cien pétalos.}

Las flores de esta clase son grauries, olurosis muy dobles, de color de rosa mas ó menos subido, dispuestas comnnmente en ramillete terminal, y sostenilas por pedúnculos erizados con pelos oseuros: las hojas son de un verde oscuro, y se componicn de ciuco hujuelas ovales: se conocen mas de rejute variedikdes. Los tallos son espinosos y de tres piçs de altura.

\section{Rosal amarillo.}

Sus flores son de mediano titmaño bien dobles y desenrueltas, olorosas, color de yema de huevo, son muy numerosas tanto que con el peso de ellas se venceu los tallos y cueigan las flores. Los tallos de este rusa] son delgados, crecen seis ú ucho piés de altura, y se hallan guarnecidos de muchos aguijones cortes, rojizos y derechos, las hojas sou amarillentas y compues. tas de siete hojuelas.

\section{Rosal canelo.}

Esta flor es muy temprana y perqueña de color rosado bajo, de figura irregular, se dá por Abril y Mayo, 
emjambra con abundancia por lo que sirre rara cerca. Los tallos son derechos, poco espinosos de cinco a ocho piés de alto $y$ de color de púrpura muy oscuro.

\section{Rosal castcllano.}

Esta clase de flor es mus doble, de color jaspeado, listndo de blanco 5 encarnado, olorosas, dispuestas en ramillctes terminalcs, florece todo el año.

\section{Rosal de musgo.}

Esta es de las mejores rosas conocidas, tanto por lo sumamente doble y olorosn, cuanto per el muso que guarnece los pedúnculis y cálices con no poca hermosura y elegancia, no obstante que sc considera generalmente por rariedad del rosal de cien pétalos por la singular circunstancia del musgo que guarneco sus cálices, crco haccrse moncion particularmente.

\section{Rosal de alrjantría.}

De esta clase sa conocen algunas raricdades de las cunles la mejor y mas sobresalicnte es la de flor entcrameute multiplicada, su color claro, su fragancia delicada, su figura oblonga, es tardín y resiste al sol sin ajarse. Los tallos crecen a mas de siete piés do altura, y son rerdosos: las hojas se componen de einco hojue. las, aserradas finamente 5 tinturadas en las márgenes de un color parduzco. 


\section{Rosal blanco.}

Do este rosal se cultivan bastantes variedades mas ó ménos dobles, y eutre tudas la mas superior es la quo so halla enteramente muliplivada; cu su centro adquieren los pétalus uu color outre carneo $y$ amarillento, mas notable cuanto mas desarrollada so halla la Hor; es olorosa y tardín. Los tallos son amarilleutos y blanquecinos, en sus estremidades, con espesos $y$ fuertes aguijones.

Rosal Alpino sin espinas.

Esta flor es encarnada muy viva, muy olorosa, no tie:1e apéndices, es duble. Los tallos $\mathrm{J}$ ramos son sin aguijones de dos hasta cuatro piés de a'tura; las hojas se componen de siete á nueve hojuelas.

\section{Rosal de la China ó mosquela de bengala.}

Se cosıocen dos variedades; una do color de púrpura y la otra culur rosado descoluridis, flurce todu $\mathrm{el}$ año y resiste á lias cstaciunes. Los tallus son gruesos y creceu hista dos piés de altura.

\section{Rosal mrsqueta.}

Hay dos rarjcdarles, de flor doble 5 de sencilla, do color blancas y olurosas dispuestas cn panojas espesas terminal, florece en vcrano y sigue hasta el invierno en que los frios se las hice caer. Los tallos. espinosos, elevados y de desigual firura, las hojas lustrosas y 
siempre rerdus: por lo regular el rosat do flor sencilta sirve para logral patrones el quo injertar ourads lusils.

\section{Rosal escaramijo.}

Este rosal es silvestre y so cultiva unicamente para patrones on que injertar otras castas de rosal mus superiorcs.

\section{Rosal enano.}

Se cultivan muchas variedades de esta especie, sus fores son dobles, de pequeño diámetro, las hay do diferentes, culores morado encelulislo, blancas, encarnadas, carmcsies I listallas tioreco por Mayu, Junio y Julio. Los tallos sun espinosıs, creccn de un pié á pió y medio y enjambra extraordinariamente.

\section{Rosal de piocha.}

Este rosal se distingue del antecedente on que tiene sus hojuolis inuy pequoiras y lais flores do colur rosado rlescolorido.

Las numerosis variedades do rosales que se cultjran cu los jarlines Ieben todos su orijen á una do las espeeies anunciadas: torlas se logrim y virim por simiente $y$ se reproducen por hijuelos y por injerto.

\section{De la sicmbra de los rosales.}

Torlos los rosales pruerien multiplicarso porsemilla y para poder consegnir las varicilados es preciso que sea isí, annque sca sid ombargo un mótolu bastante 
Jento que hace espernr, pero es el úuico modo de conseguillo, de modo que solo se echara seuillero cuando se quiera adquirir una nuera especio jardinera; por senillero tardan de tres á cuatro años, cstos.se dispondrún al raso $z$ con tierra suelta benefictalia y custaneiosa, se entieiran las simicites ála profunclitad de un redo escaso y se cuida dol mismo invdo qne cualquicr otro.

\section{Irulliplicacion ner acodo ó rama.}

Ios mas de los rosales pre!den por estacas ò rama I por ncorlo ó mngron, pelo esto se hace con las que no cnjambran $y$ carecen de hijuelos radicales, lërtiles I barbados: la mosqueta sc propaga con suma fincilidad por estaca, escrijiendo los tallos renneros del año anterior que se divide en trozos de media rara; por el talon ó jié se cortan en jié de calbra, $s$ se introducen en tierra, cuillando siempre dejar fuera algnnas yemas para que brote hijas 5 tallos, al paso que las otras de tierra producen raices. Los parajes mas acomodados para esta maniobra son los sombi ios y luúmedos: en situnciones ignales se encouban ó acodaulos tallos de las castas que lian de aumeutause por acodu. Estas matas tardan en brotar raices buenas y suficicites lo ménos un año jara que juedan trasplantarss de asiento, y otros acodos al contrajio, requicren dos años, para que se hallen en buena disposieion.

Los rosales se trasjlantan cn cuarteles $\sigma$ cundros do ticrra snstanciosa, beneficiada y bien cavada, en situacion asoleadas $y$ sin sombra de árboles; se plantan igualmente el las arriatas encespedados y demas pa-. rajes mas risibles del jardin mezelados con las demás 
plantas zue se adaptan para el allorno de les florer.)s. En los cuadres se eoleca eada planta á dos ó tres piés de distancia, abriendo les hornos de dos piés en cuadre por uno de profunditar $y$ en calla ingulo so eoloen un pié dle rosal barbado. El tiempo mas prejio para trasplantar los rosalcs es por el otoño aunqua por el inrierno pueden plantarse igualmente, 5 podar fucetemente para que asi prend.ın mejor $y$ retoñen con fuerza.

\section{Mulliplicacion por injerto.}

Tambien se multiplican los rosales nor injerto, come otras muchas plintas 5 árboles: los injertos se puedon hacer do varios modos: pur arnoximation, jor endedura, 5 por escudete. El primero runsiste ó so hace rebajundo clel tallo una pilrte á carla una le las plantas que se raşan it injertiu' y reuniéudulas para que suelden, El de endilura, of que gencralmente se usa para los arboles, si es gruesose sierra primerạ. mente con un serrueho tino, juitíndole despues la parte molida por el serrucho, luego con mir mazo y una euña de madera dura se abre al fioneo lo necesario para introdueir la pun, mas si fucse delgado so abre solamente een un cuchillo profumilamente por of medio, despues la pua que se peno alli, brota maravillosamente ramas hermosas y lozanas. La jua ó rama ha de tener lo menos tres iledos de largo, y ha de to. ner tambien tres buenas yemas; se corta esta pun en forma de punta per el lario mas corto, el eorte ha do ser de un dedo y medio de largo, cuillando quede bien unida la eertcza de les lader que forma lia punta; la parte destinada a qlodar fucra, debe sor mas aneha y 
gruesa que la que se introluce; se ha de colocar tan ajustadir en la abertura esta punta, que la corteza do la pua quede pelfectamento igual cou la del Fástago y que ambas curtezals se correspondan de modo que subiendo la sábia del pié se apodcie fácilmenté dé la pua introduciéndose en ellà luego se atáá el árbol 'ó mata ingerida con una majagua ó arique sin mover la pua, cubriéndola bien con tierra becha lodo, mezclado con musgo 6 heno muy delgado, 6 con arcilla aujazada con escremento de vaca: teniendo presente que antes de poncr la pua se ha de póner como dos horas en agua que asi preude mucho mejul. Este modo de injertar suele llamarse de corona, con solo la diferencia de poner las puas al rededor del tronco entre la corteza y la madera. Tambien se hace esta operacion al contrario, es decir, que al tronco se le hace la pua 6 cuūa y á la que antes era cuūa se le hice la hcudidura 6 mortaja que ajuste perfectamente al tronco.

Tambien hay otros que le llamau de barreno y de cañon pero csto además de no dar sicmpro bueuos resultatlos en particular el seguudo es difieultosísimo: pero sobre todos los injertos el mejor; mas scguro $\mathrm{y}$ fácil cn el procedimiente es el que grencralmente sc usa en rosales, arbustos y aun eu ȧrbules siemprö con buen exito; para lo cualsc busca una yema buena $y$ se saca dándolo un curte superior horizontal á distancia de tres $\delta$ cuatro lineas sobre la yena, $\ulcorner$ luego se danı dos cortes diagonales que veugan à unir por abajo de la yema eu figura de $V \cdot \sigma$ cscudo tríángulo con cl corte que se dió auterior, quedándo la sema en cl medio, hecho csto se oprime ligeramente con los dedos la parte leūosa que se cogió con los cortes, y se veráa que al despreuderse queda la jema en la corteza 
ó leño desprendido, seguro sa de esto, se hace una incision en forma de T, en la parte en que sc ráa colocar el injerto, se lerantis la corteza por la punta que forma los angulos de lia T. en su centro, $\nabla$ se introduce la corteza solamente que contiene la jema del escudo, $y$ así cuidadosamente el resto, concluida se liga con majagua ú otra cosa suare, y siu apretar mucho la herida, embarráudola como se dijo anteriormente y cuando se considere esté bien preso el injerto, se le quitarán inmediatamente las ligaduras para que no formen rebordcs ó zanjas en la corteza, El tiempo a propósito para este iujerto es Junio, el do pua por Febrero y Marzo y el de coroua á principios de Mayo.

El injerto de planta cs más difícil àe conseguir, en razon a que este consiste en sacar la sema on círculo dc una rama nueva, lnego se hace otro corto igual exactamente en el ramo en que se ra á injertar, y colocándolo perfectamente la yema como el engaste de un anillo, despues se sujeta cou la mezcla jardinera y está concluida la operacion.

\section{Cultivo de ios rosales.}

Los cuadros do rosal doben cavarse por e! otoño ó jnvierno, y es más ventajosa si se repite por la primavern, tambien es muy conveuiente abonar el tcreno con mantillo.

Por el mes do setiembre so despuntan y entresacan los ramos y se cortan todos los tallos roviejos y sccos, con lo cual brotan tallos nuevos y toman fuerza ántes dol invierno. Los rosales de todos tiempos deben podarse dos 6 tres vocos al año í fin de lograr rusas on 
varias estaciones; la puda bien manejada es muy útil para las plaut.s y unce reproducir cou fuerza las flojes. Los riegus son necerarios, pero no han de ser demasiadamente copissus, [urque con la humeded pierden las rosas mucha jarte de su olor y color.

\section{Enemigos de los rosales.}

Las orugas, el pulgon $\mathrm{g}$ la carañuela verile causan estragos cousiuerables; palla evitar estos inconvenientes se puede hacer una infusion de tallos de saúco y se rocian las matas y sino surtiere efecto, se hace una legía fuerte y con ella se riegan las jlautas, ó poniendu a hervir partes iguales de oriues y borlas de aceite y estando fria esta mezcla se ricga con ella ó con agua podrida de cangrejos, y últimamente con agua de cal se hace una jufusion de talinco y se rocian las matas que no quedará ningun bichu.

\section{De la r.ila.}

Las flores de este arbusto son pequeñas, olorosas colocadas eu grandes panojis tertuinales, su color de púrputa azulado, rojizo, azul descololido y blanco. EI tronco se levanta hastil 16 piés de altura, sus ramos son opuestos y muy poblados de hojas grandes, opliestas, acorazonadas, puntiagudas, lampiñas, enteras y peeioladas: hay de varias especies y fioreceu por Abril y Mrayo, cn cuya éfoca adornan mararillosamente los jardines por la hermoisura y ftagancia. Sirven estas plantas para formar parcdes vivas ó cercas, bosqueci: llos, glorietas ó merenderos y do todos modos agracian singularmente. 


\section{De la Celindı ó geringuillu.}

Crece este arbustu a mas de seis piés, produce numerosus tallos ramusos cul sus bojas opuestis auradas, puntiagudas, tiumente debralas, 5 a!go amarilleuta por el envés. Las flores nacen en cspiguillaz terminales ó ascilares y son ve color blanco mng olurusa tal que su escesivit fragancia no la grteden sufrir las persunas delicintils

\section{Cultivo die ias dos y su multiplicacion.}

Estos dos arbilstos previlucen en toda clase de terreus. Se reprobluc:n con ficilidad por hijuelos barbadus 5 por estacas I por semilleros, pero estas taudau res años palri poderse trisplantar, de monto que fara alulitr mas vrevo usan do los dos mudus jumeros y pallia eso se buscan los terrenos entre sol f sombra: pair que ahijen con abundancia se podan ó lescabezin lus ramus y tallos para facilitar la regetheion. Lats estacias barbadas 5 mugronesse sacarán á lus dos aúns y so rasplatuta:cin do asiento. Con los t:llo: do estos aibunstus so forman en los jardines Firins indornos cemo abauicos, encañados, y otros muy preciusus.

\section{Del Resctan}

Las fiores do este arbusto sou de color rosadas, de un color muy snave 5 fingiute, dispuestas en espigas tlojas. Los tallos ritmosos crecen de cineo á sois piés, sus hojas son muy ruenuditas espatuladas cuteras, aunque varian mucho de sus formas por el cultivo. 
Siembra y cultivo.

Se siembra al raso desde Marzo hasta Junio, las plantas que se cultivan sin padecer la trasplan. taeion se crian mas vigorosas y lozanas; prevalecen en todo terreno, $\bar{y}$ los riegos serán moderados, aquí en este clima es planta perenr.e, si quies e trasplantarse se hará siempre por Marzo y Abril.

\section{-De la Ortencia.}

Este arbusto hace pocos años que se introdujo su cultivo en los jardines es planta tan preciosa, vistosa y de las mas hermosas que se conoeen, tanto que meresio la admiracion y aprecio dc los botánieos y floristas de toda la Europa y procuraron aclimatarla, es natural dela China y del Japon, $\mathrm{g}$ aquí en este clima se da perfectsinamente. La ortencia es un ar. busto que crece de tres a cuatro piés de altura, sus tallos son ramosos, gruesos, rollizos y derechos: las hojas opuestas elípticas, de seís á nueve pulgadas de largo, y de tres á cuatro de ancho, aserradas, lampiñas, de un verde lustroso, algunas veces un poeo rojizas en su estremidad, señaladas con grandes vervios; las tores terminan los tallos y forman unos grandes corimbos redondos, al principio son verdosos y despues so vuelven de un color encarnado muy hermoso, floroco desde Abril hasta Octubre.

\section{Irutlipticacion ó siembra.}

No se puede propagar por semilla ó al zoénos has- 
ta ahora no se lo podidu por que nu llega á prerlecule

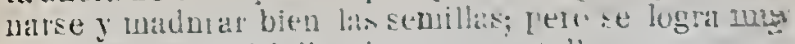

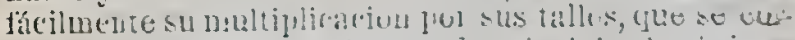

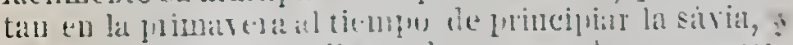

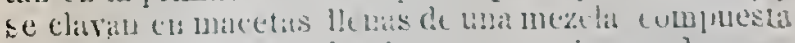

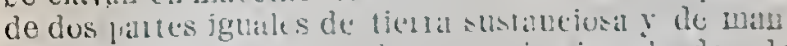

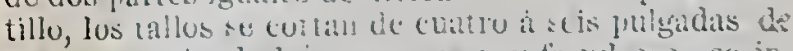

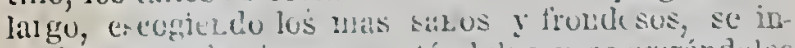
troducen cu la tiellat apretádulos y astrurándoles

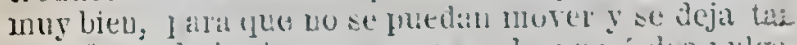

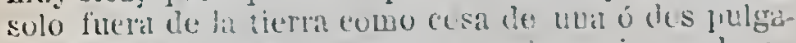

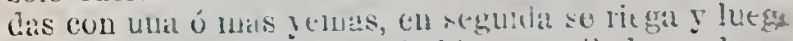
se coluca tu un icses vaturio biell iembilade, y el custe sugerior se cmbatrit con berro arrilluso inezelade cou boñiga de vatá lalsta gute cienal y cicatrice.

Iambien se multiplican por acolo, jata lo cual se esticndeu los tallos con mucho cuididu cli tiestos qua deben ser suficiente grandes $1^{\text {tal }}$ al el intente, se doblas un puco la parte cotcrialat fara (jue arratguen me jur y se sujela c:m hurguillas de malrra fara que queden muy sujeto: y no se fluediu morer: al tienup. de bajar y dubiall extos tallos se tendrá comidalo de no desgajarlus del talio princifial, ni romplerlos lo qua

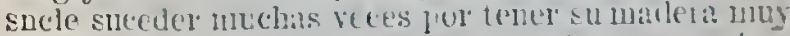

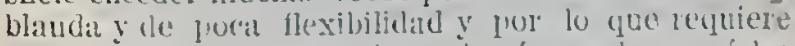

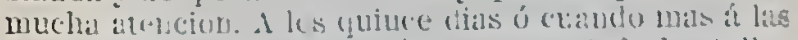

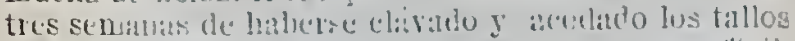

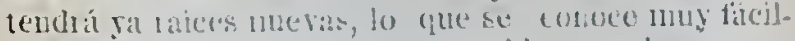

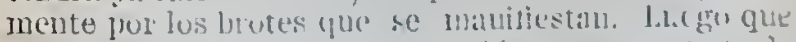

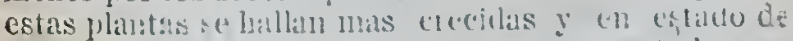

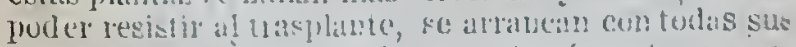

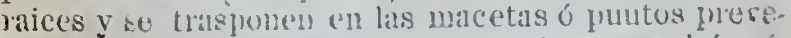

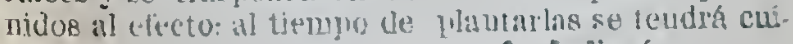


darlo de estemier bion sus raices, luego se le echa tior$\mathrm{ra}$, so lo aprietio con la mano tonlo al rededor de la planta; se acaba do llenar, $y$ eu segrulita se le dá un abundinte riegro, rupitiéndulo on dos ó tres veces: pero no echamlo mucha cantidad de agua á la re\%; de este molo yueliari osta mas comprimila y apclmazala, y la planta tuals secrutit. Degl mistnu molo se trisplantan los hijuelos ó retonos gue se sikerin de la planta malris.

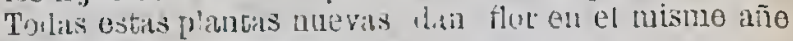
á fines dol verano y en utuino.

\section{Cuiltivo.}

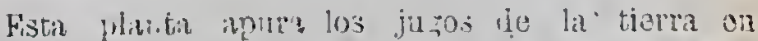
poco tiempo, convione renovar la mezcla del abono torlos los años, dospues de laber pasado las flores, se labrará lit superficio de la tierra cuare do se halle endurocidat $y$ furno costra, por razon quo gara prevalccer bion osta, necosita que la tierca ostó susranciosa y con bistante mantille de caballeriza muy consumido: nocesita rogarse á monudo particularmente on las estaciones sccas 5 caleresas; el sel la per judica cxtranidiuariamento y resisto perfectameuto al itto libere los ftios del invierne.

\section{De la relama de jlor.}

Lats fores nacen en espigas grandes on la ostremidad do los rames, do coler amarillo, amariposudas, oloresa. El tallo crece hasta ocho piés de al tuia y produco muchos rames delgados, derechos, fluxiblos, vordeg y rostidos de hejis pequoñas linoardas, altoruas y 
alguua rez opuesta. Florece este arbusto por Mayo J. Junic, so destina para bosquocillos, encresparlos, orillas de calles y la arrarian cos sus fragan tos fioros.

Sismbra, plantio y cultivo.

Se multiplici este a rousto por semilla que so sierhbra por Majo y Abril eo semilleros de tierla ligora, cubriúudolis con una capa de mantillo del grueso do dos deilus: no exijen mas cuidados quo el repartimionto arreglato do loz riegos, algunas labores, quo al tiempo que athequen lit tierria destruyen lis yerbats extruñas, si natoiosen muy jubtas se eutresiacin, dojando en el scaillero hasta el segundo año las quo so lather en buesta disposicion para el plantio. Se trazplantan por "atoño ó lik primivora, so sacan con buenos céspos les procuranilu sibear la raiz contral ontera, siu lo ental sucleu periarso muchis plintus, so

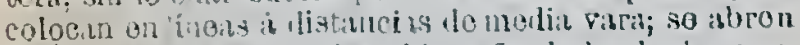

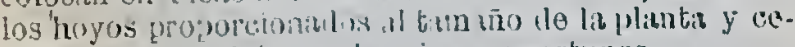
pollon, $y$ se inminiatr.n los riegus opmtunos.

\section{Inisa de Queldits.}

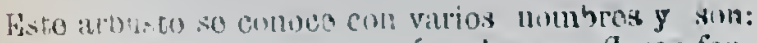

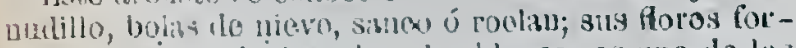
man eopas terminilos, do color blamen, os uno de los principales atorum on los jurilines. Tras tallow crowen

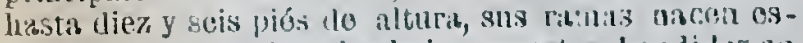
parramadias y produco lay hujas optostas, handilits en tres 0 cineo tirass itgulas y fostouadas. 


\section{Mulliplicacion, plantío y cultivo.}

Este arbusto se propaga fíeilmente fror simieute. pero es inucho mejur por acodo, y todavia mejor por rama, por el gride ahorro de trabajo que resulta do esta últiuna operacion; todos los años se les quita toda la rana seca y una fuerte poda eada seis años; tiene la propiedal de que cuando es muy viejo, rnelre í renurarse con solo terciar sus ramas, y lloduce tanto. como si fuese joren.

\section{De la falsa Acacia.}

Esta florece eu Abril y Mayo, las flores salon cerea do la extremidad do las ramias, en racimos grindes, axilares: son blaneas; olorosas $Y$ muy vistosits, es nattural do América; su tronco en derecizo, muy poblado de ranas alternas que lorman una cupa hermosia ereeo hasta tremta piés de alto, á la baso re cara hoja geha dos estípulas espinosas muy duras y agudas; las bojas son pecioladas, alatlas con jmuar, compuesta lesdo treet hasta reinte y eineo hojueliats elipticas cie mas de una pulgada de largo y de veho de aucho, y de un verde claro.

\section{stembra, plantio y cultivo.}

Tste arhol se propara uny lícilmente por los hijuelos ó retuños que enn tantia abumblaueia protuceu sps riliets: $y$ tamben por semillas gute se sieubriu por surcos sumeros on Mingo, ou parijes resgumbados de! 
sol; la tiera la de estar bien labrada y desmenuzada, J se eubren con uua tanda do mantillo rel grueso do sais líneas, rogándolas á menudo. Estarín on disposicion le trisplautarso de asionto, tanto parib formar callus ó lo quo mejor acomode, desile los tres hastir los seis anos, se hace csta operacion, por los meses do Enero y Fubrero y principios de Mrarzo. Esto árbol sirvo de patrom para ingertar la acacia rosa; so ingerta de ondidura ó pua en Fubroro s Marzo, y do escudo al vivir on Nayo y Juuio.

\section{Del arrayain ó murla.}

For arayin se tione por una variedal do la murta poro sus hojis son constantomentc mas pequeñas. La murla us III arbusto de culatro ó cinco piés do altuta muy pamuss; sus ramos son flexibles, con muehas hojas oprestas, lanceolidas do un rerde lustroso, tampiürs, durns y porsistuntes. Las floros son axilares y solit: lias, hliueas y con numerosos estambres quo están incertos en el ciliz. So multiplican por sus semillas, por acoio, por estaquilla, y por la separacion do sus hijuelos, dol misuro modo glue ya queda indicalo on atros cultivos.

Omito lat deseripeion de otros virios arbustos do flor que se cultivin en lus jibdines, porquo sus cultiros convienen con los ya usplicintos, y entro ollos los mats sobrosibliontes son ol grobo do orw, que se multiplica

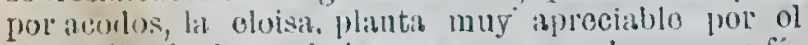
olor deliculo do sus hojas, y que so produeo muy fícilmonto por sus estaquillas ó ramas. 
Plantas volubles y irepadoras.

Las plantas de tallos rolubles, sarmentosos ó leñosos y trepadores, que se enlazan y enredan, y sirven para cubrir $y$ adurnar los emberjados, tucanados teropletes, senadores, grutas, festunes, guirmaldas, alamijeos, espalderas, ete., exigen tolas un mismo cultivo con nuy roca variacion. y jor lo tanto liss he reunido en este auticulo. Jas privejpales son el jazmin blanco, jazmin trompeta, lit clemati de vidalba ó yerba portio. sera, pasionaria o granadilla, aristuloguia, filjol cabs. llero, madreselvas, la redra y la esterja que es natural de Héjicu, sus tallos son delgalos, muy ramosos de mas de dece jiés de ling"a, trupa flor los cuerpos vecinos álos que se agarran, es de un verde lustroso: sus fores son rogizas I mas commumente de bin ljuleta claro con dos líneas blabcas,

Siembra y cultivo.

Los jazmines blancos $y$ americanos, la clematide aristuloquía g madresel ras, se siembran al raso en eras de buena tierra por Marzo y Abril, se esparraman á puño las simientes, que aran con el almozcalre juproreionando que queden culviertas hasta el grueso de un dedo con arreglo á su tamnno: deben regarse á mano en los semilleros hasta gue hayan medros que puedabi resistir los riegos de pié: las escardas, entrecavas y demás cuidados comunes á todo vegetal no se omitirán mientras permanezcau en los semilleros, se entresacirán Jos parages espesos se dividjun las plantas ya crecidas para reponerlas una por una if tio de que ad- 
quieran fuerza 5 rignr $y$ se crien lozinas: a la tercera rez de su redor pudrin trasplantarse de asiento al aire libre, su cultivo consiste en arreglar los tallos sarmentosos, de mancla que no deje clanos, cu escamonGar y li myiar lus ramus secus y dañudos, y en esquilar á tiempo las ranas subrates de lus festones y guirmaldak, y demis cyue exigen este cuidido.

\section{Mullighicacion mas rolchle.}

Para que ser mas prouta su regetacion, se fropiga

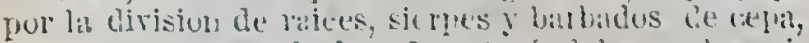
tambien for rama de dus anu clavinclelas en lis orillas de las cercas y sitius acumudadus al wejeto; $\quad 014$ la primavera se anmentan tambion los individuos ce es-

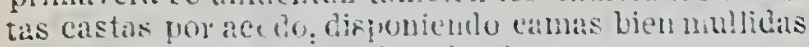
en lats inmedirciones de lits glantias.

\section{SECCION SEGUNDA.}

De las yerbus y plantus uromálicas.

Albshacs, la hay de varias especies, de logjas tinas,

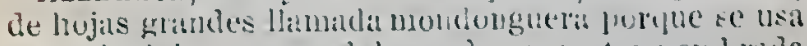

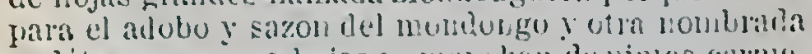
mulata porque sus hojas se malne lan de pintas comme-litas; las tress clitees tien en y exhalan mucho olor. Ee sicmbran de semilla y de goijos; Inegu que estén grandes se despmutan paral gue a duchen y lormen gram copa.

Batsamisa, se siembrat de cstilet.

Cakquesa, es planta rastrura, sus guials van arraigando al estenderse, se siembrit de gajo, ('s plantil suy medicinal. 
CAÑ Da Llitos, esta planta se reproduto por hijos zuo brotan del pió, reginiero terrono ahonalo enn mansillo 5 riegr enstante, tieno uncho aroma, sa olor es

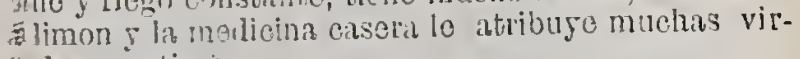
bades curatiris.

GERATOO DE knsi, so propaga te gajo, ol mucho rioat la perjudicat. el ierrem en que se siombra debo mezelarse con us tercin lle arena, sus bojas tosplion wo olor á rosa ile dicjanciría.

INCIEXso, sc propara de rajn, ol rickgo y terreno como ol anterion, so le atribijen vithdes menlicinales $\mathrm{y}$ za arom so paroce m icio al cuo desplite el inciensoreeina.

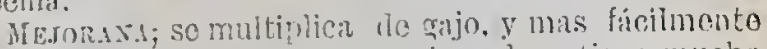
for aculo, recpien' terrenos abonalus, tiene mucho zroma $y$ es planta molicinal.

Rovero, rosile la nas remota anligüentarl, todos los Jaturalistas han atribuich it estir planta muchs viptu-

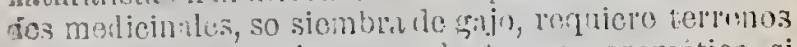
pedregosus y poog riego, es phantat my aromitica; si xe quiere cultivar en macotas se preprara lia tierra en Ia proprorcion signiente:

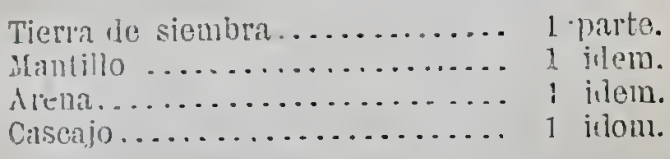

Tolo se mezela bien; la planka creceri, con gran 10 . mia $y$ rerdor.

Rens, planta medicinal muy otoríica, se dí fácilDente lle grajo y con mas segurtial! por acollo, requicтo poco riegro y termos abonatos mezclados con aro- 
Dat gruosi; cn el vorano la ataca un gusiuo negto con manchas blancas quo procrea 5 se mintiano do los ronuevos y concluse pur derorar to la la planta, hay quo quitarlos a tiemao pora salvar la planta.

Tusilso, se dit de gajo r como el antorior requicro pon riegu y terrenus tercialus cos arena, os planta ounrifica y molicinai.

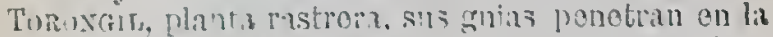
tieira en dombe arragan brotanilo reteños, requioro terronos abonulis s frecucatemanto rem vidos con to cnal y riego abumlante se propag prodigiosamente: batil arancir estos renueros con iaces y trasplantarlos para rupro lncirlo: so lo atribayen muchas virturles wo liciniles.

YeuB L-BUEx 1, es muy cunocila estal planta, pues so cultiva con las hortalizals 5 so as on las cobinas para s.tzonatr las cominilaz. es phata matropa conola ante-

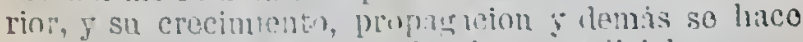

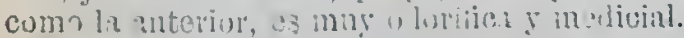

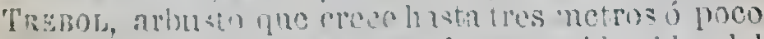

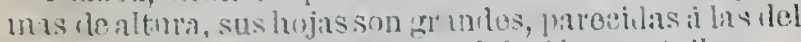
tabaco, echn muchos ronueves lel pié sus tallos son largios y delarlns. se propaga fícilmento sacandn estos renucros cor laicos g tieria y trasplantinutolos; ro-

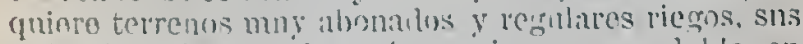

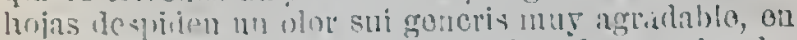

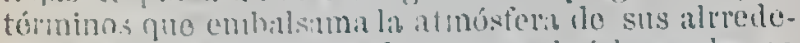

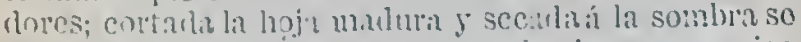
haco llesible y elística, conservindo siempro su rico arom q que trasmito de un molo premanente á los cherpos con quiencs se pone en contacto, dos ó tros hojas

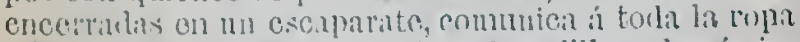
sú cica $y$ suave hagancia y libra do polilla y domá in. 
sectos njeivos. Algmos funarlores, colocan estas liojis deutio de las regigus rlonde guardan el tabico sine lunaln, al que cuntunica su agladable e sencia is asegruman

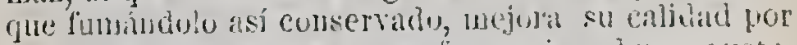
buenc que seal, aumeuta su fiaghncil y unen gusto. cultivese en grande cecala y dese á cuivecr á lus cx-

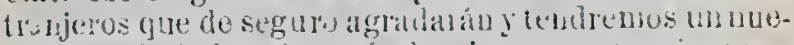

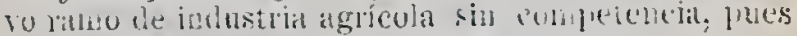

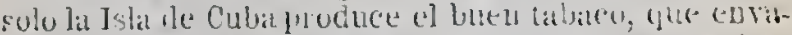
sadu cutre hojas del balsimico trebol allmentará su fima iniversal.

'lévgase fueschte esto, fara que cn la jumera kx-

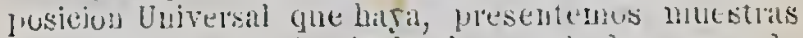

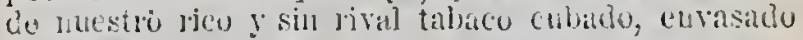
en lit lucma cepliindiat.

YEKBA J.CIsd, arbusto que crece hasta metro y lule-

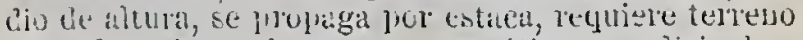
abouado y ricgo, blata muy aronática y mediciual.

Ak'tmiss, lituta silsestre que se repruduce de semilla en ciertis lucalidades, prefiere Jus terrenos anci1 losos y secus, arece geneminerte hasta un metro do altura, no se cultiva en lus jardinces pergue su flor no

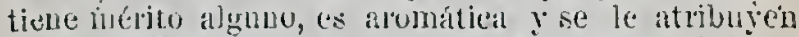
Jropicdates curativas para algunas enfernedades.

Apasu'se, arbisto pequeño gue ce reptruce de se

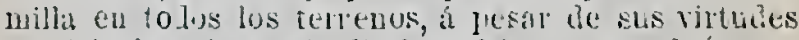
netirinales uingun jardin lo cultiva y cuabdu'se necesita prua remcdio hay que buscarlo silverte, es muy aroubitico.

Clapblex (flor de muerlo). Se sitinbran de semilis por Abril y hayo, la hay que producen tores anarillas y otrus walminuela, sus hujals y fores son odortioas, unty vistusas, de inodo que es Lueu adorno frana los 
jaruines, requiere terrenos abonados y riegos: es plantit mus medicinal.

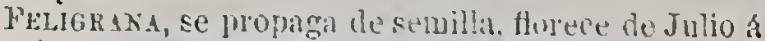
Octubre, requiere tertenos a butiadus ! regulares ricges:

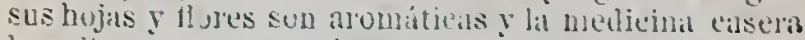
lat aplica patra curar a! Igunats dolencias.

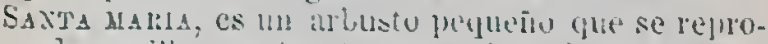

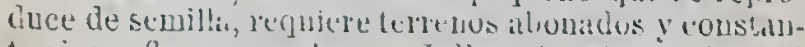

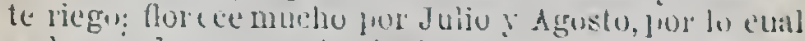

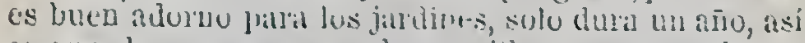

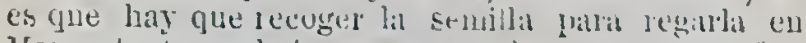
Marzo; tarito sus lojis como sus llores son unuy tragantes, olor agrathble? yuy medieinal.

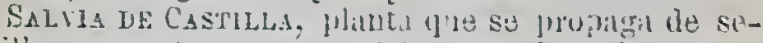
milla y por estaca, es arumitic a modicuial.

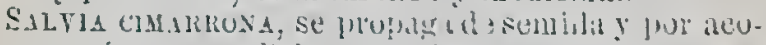

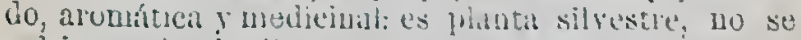
cultira en los joldintes.

SABE LECCIUR, se juviaga le: smilla, es un arbusto pequeuo mug anonático y nevelicinal; es phinta silvestre y no se cultiva ea lus jullues.

\section{SECCION TERCERA.}

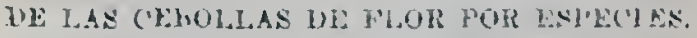
Anemone.

Dos sun las especies naturales de esta jhanta ylae han groporcionadu tudas las variedades que se cultivan hoy y adornan dadarillosamente los jindines, com sus diver'sus y brillantes matices. Ias gue puoducen la liu. ja aucha, heuchdat cumo ?us itedus de la mano ! la sj-. miente launda; es indigena de Italia y Suiza, ! todats 
las de hoid mas fina y recortala, ralicales do tros on rama y doseonpueatas, deben su origen do Constantinoplit.

Con ol cnltivo so lia logralo una infinidan do colores, blanco, encarniulo, carnesi, color do rosit, amarillo, morado azularlo, porceluna, eeniciento y manchalas y listarlas con torlos estos matiees: las flores soncillas y somilubles pro lucen sinionte, pero las dobles no, por careccr de estambres.

La raiz de esta variaria plinta es tubcrosa, agrumada y designal, mala el esterior y blanquecina por den-

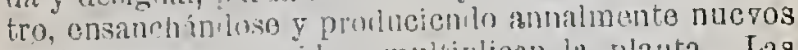

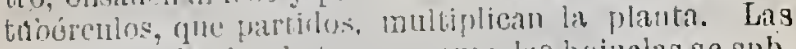

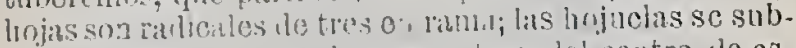
divilum reruiambante de tres an tres: del contro do os-

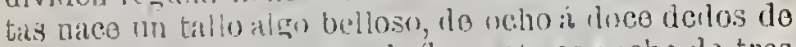
alto. terninah mor una sula flor, esta os ancha do tres

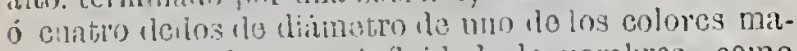
mḯcstalus, les dan una infigilat do nombres, como

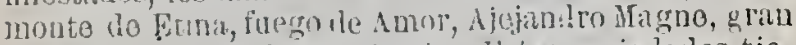
tirtaro, Galatrot, el encimto oto. W-tas variedades tionon un tirminn de durarion que no pasan do quinco años, pasalo ol cual, bast.tritean ó se pierion las raices.

Stembra para conseguir la crbolla.

La infinilud de variedades de esta planta sc obtieno por semillas, y por este méidio no solo resulta su ronoveion antes quo ompiecen id degenerar, sino quo tambien sologran otras michas especios jarlineras ntuevas, mils ó menus fistussts: los scmilleros so lisponen on misnes lovaritudus pić y medio, la niezcla do la tier:a, so hari dos partes de mantillo, una do arona $y$ 
Inedia de tierra virgen, todu lien mezchicer revuelto antes de efectuarse la sicubra, se allama jerfectamean-

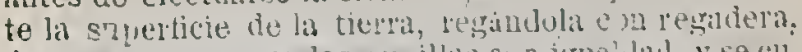

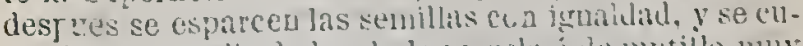
brirśa con medio dedo de la mezcla ú de mutillo mu!y cernido, Juegn se lo daná ur l'jego moderido con regraderi, resguandiradulos ded exeesiro ealor por Oetubrey Noriembre. r le emplezar brotar simentes y signen regetando ?...sta Juno: a!gumas dan flor desde el primer ano, has frutits jermanecerin en el semillero hasta : : lito ygur emplece el tallo á perelor el jugo de

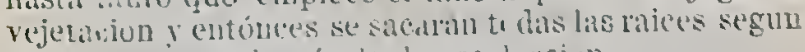

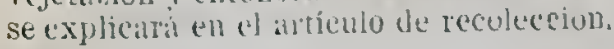

\section{Plantio.}

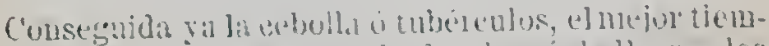
po de platutarlos es a ti!nes do Octubre a de bibero; los Jlantios so harab de vioño, en los que sa muetell from-

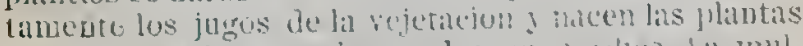

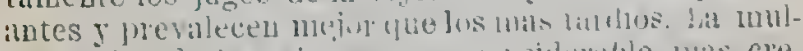

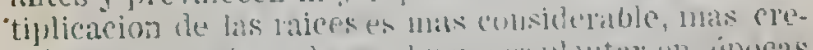

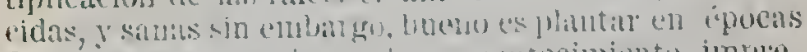

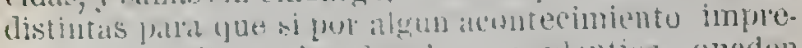
visto nuse dieren lits de atgunus plimtios, queden

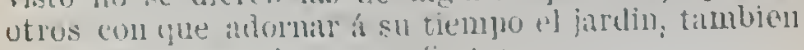
fara que se succelam mans if etrals.

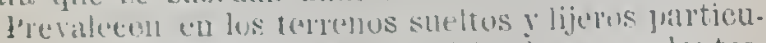
farmente cu Jos que no se lian eultivalo estas plantas; en los terrenos finertes, gredusos y compactos, 110 eon-

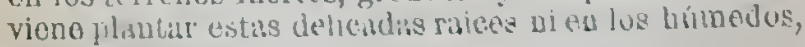
porpuo so pierion. 
Cullive y recoleccon de raices y simientrs.

Las escarias so practicarán con freetencia autes y despues de nacidas las plantas, majormento poc Fobrer() y varzo, díndole una labor á la tierra, almocín. dolit con al almocafroen los intermedios; pero no profuncitando, a fiu re no herir las cobollas: cuando están en flur, conviene rogarlas á menuto resguardindolos del mucho sol que las marchita on poeos dias, forocen on la priunvera $\mathrm{y}$ conservan sus flores por esnacio do do cuatro ó eiueo somanas.

luego yue pierilen su jugro los tallos y hojas, ampio. zan a marchitarse, que coiruntuente es por sunio y Julio, so sacan las raices do la tierm, eu clias socos y que esta tanbien lo osté, cireunstancia nocesaria paria la couservacion de estas luices, guardiululolis de un año para otro.

De las sencillas semidubles, sa seunalamin las plantas de más vigor, lo flor ancha y do colores mas viros para la recoleccion de ias somillas: entre estas doben oseojerse las que crian el tillo recto, alto y outre gruo. so: los pótalps anchos, redondeados $y$ los colores brillantes; los oscuros y matizados son los mejorcs para osto: luego que tengan madura la sonuillas se cortau las cabeztuelas con alguna porcion de tallo, no desmenttzindola hastit quo so soquou y curou porfectamonto í la sombra.

\section{Enformeduates y enenigos.}

Lass enfermedades conocidas quo padecen las cobollas do osta planta, son la vajor, unolu, podrodumbre, 
accita, y las caries 6 cancer. Tuta raiz hueca $y$ en la rual se alviertan agujeros que penetran al interior, ó rave zo halla carcomilha en el nacmicuto do las rairilles, estit dañda, lo cual so ha de contar torla la parre hasta l'eral á lo sano: la excesiva bumedad las ace. da, y se conoco en el color amatil!o de late hojits y st-

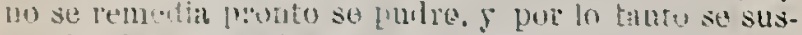
foralen los megos hasta que empiece it adquirir una rejetacion l walla.

Fisea phanca tieno una gorcion de cuemigos que la hatem muchu dintu, las ratas y los ratunes so romen las raices is tubreulos: el alactan do jardin causit grandes daños cu los semilleros, uma la tierra, cortis collos los mores tiemos que le impicien el paso, y de stas resmltas latco perecre lat phanta, al temug de dar la cava sè bus.

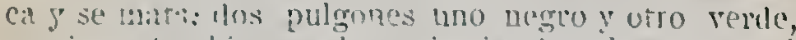

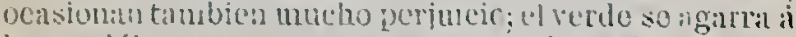
los pecólos y con su trompa extlice la savia, ol neure so introduco dentro, le las flores autes do ibrirso estas, se escmirio entro los pétalos, los ruo y cortir poco a puce: para desiruirlo conviene lavar bion las plantas y echitilo bastanto hollin ó tabaco en polro: en los semilleros hacen tambien daño, para precarerlo so ccha una cinpa to hullin y palouima bien mezclata. La orugra llamatala rosquilla. de color pardusco, so introduce íclus ó tres lineas y va rogendo y cortinulo poco á yoco lit plant.1, $y$ su couoce cuando so caon las hojias oxtorimes: exta so busca cscarvando al rededor do las raices hasta que so encuontra. Los gusanillos blancos que so ancuentran en la basura, atacan indistintamonto lass hojis y las raices, ai so les uncuentran on las hojas so lavan estas con agna y jabon, y esto lo llestruye, poro si catín on lass raices, es preciso desculrirlas, so 
sacan cou un cortajlumas, cortaudu tambien la jarte dañada fror él, y lenando el hueco con tiena nueva, y en seguida se regará la plinta cou 110 cocimicuto do tabaco que lus ficabil de destruir. I'tra pesemales tambies de la labusa, que les hace mechu dáno, lubla noche se les ceha uwa capa de ceniza.

\section{Harimoña ó franccsilla.}

Los colores mas comunes de esta flor son, moradas, regruzcis, colur de calë, cenicientas, aceitunas, fajadas de blanco, color de rusa, de fuego, evcarnadas, naranjadis, de purcelaua, blancas J do color de carve ete. Se tienen jor las mis subresalientes las de tallo grueso, de caturce dedus de alto g. terminado por uma hermu:a flor do dos ú tresi deros de dinmetru ú algo más, Las hojas radicales son Lum.cosas, y se hallali sostewidas pur feciulus bastan te langos, del sobacu de ellas mecen utros ran:os mas detgados, lus rue juccicen sus flores mas freruerias. Liel ralz es tulerosa innmada,

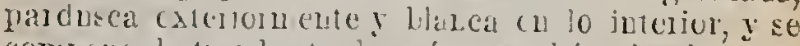

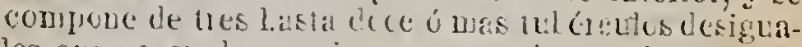
les que naceu de mu mismo Irutu, tieren en su áfice, una, dos ó mis jemas lecinelas cubiertis con felos parduscos que ergruesan ch la tierrat y en cida hat juoduce utra riziz subre la antigua que jerece ciesplos de haberlo suministrado á las nuetas su juge.

\section{Sicmora.}

Itsta claso do plantia so multiplica por las raices socundurias que vacen de la cebolla irincipal y tambien por su semilla, yoro se propaga mas fícilwente 5 mu- 
cho mejor por la raíz, flureciendo las plautas con más brevedad, se mantienen las rarjedades sin degenerar, F cs el único medjo que queda pisar lil multipliciciou da la flur doble, $\mathrm{y}$ de todas anuellas que 110 dan semillas. Las siembrals se efectuan í íltunos de Agosto ó principios de Setiemin'e, del mismo mudo que so dijo auteriormente para los auémones, lo nismo que para ul plaritio, cultiro, reculecciou de raíces y semillas $y$ sus entermedades y enemisros.

\section{Del Jacinto.}

Las ftores de esta especio las har do varios colores, las más apreciadas son las azules y blancus, muy olorosias, se hallan colocadas á la distam ia unas de otras descle una hasta diez líneas eu la puntia del tallo: de lo alto de la cebolla nacev de cuatro á oulho hojas radicalus, largas, augostas, acaualadis, lampiñas, de un vordo relueiento y algo caruesas; del ceutro do estas so eleva el tallo do doce dedos de largo, rerle, lustrinso, jugosu, rasi cilíndrico, hueco, lleno (le médula, de tres a seis icdos de ditmotro en su base, $y$ disminupe progresiramente hacia su extremidal snoerior, ci númere, de flores varia considerablemente, calla tallo produce de seis hasta troiuta ó mis, segun sus diferentes variedades. La laíz es una cebolla o sea mollo redundo, rompuesto do muchas túuicas jugosas, quo se emruelven y cubren unas á otris; las Axtcrioros de telillas sceas y rojizis, y has interior'es mís gruesas, caruosis $y$ blancas, termiua en su base en unil porcion carnosia, sólicla, de la cual nacen sus raticecillas tibrosas y blaucas. Los colores de las flores le los jacin tos alle. inás do los dos reforidos so eonocon encarnatios, colol 


\section{$-3 \cdot 1-$}

de fnego color de rosa, blancos con el ccutro color de caña matizarlos de finego 5 chcamalo, blancos con manchas y fajas purpurinas, moralos y color de porce lana: los sencillos prorlucen unchis más flures quo los dobles que se dice anterior, pues cstos il veces jasan le cuarenta a cincueda en mala tallu auncuo uás pequeñas, son uụ vistosas, de culures muy vivos $\mathrm{g}$ exhalan un olor nits fuete $y$ aglatalsle que las clobles.

\section{Sicmura, plantio y cullivo.}

las especies jarclineras se perpetuan legitinas y sin sariar por medio de los bulbus ó hijuelos que produce la rafz madre, lo que no succde por la repruluceion de sus semillas, pues rarian tan extraorclinariamonte las plantas, que aprenas se encontranin dos que se asemejen cxactameute siendo las semillas de una sola mata: las siembras se haràn en cajones cumo se cliju jara los anémones; la mezcla con que debe llemarse estos sera uni parte de tieria rejetal, tres de mantillo: una de na ut:llo de hoja rle írboles y dos de arena fiua; estas se debe tener echa die un año paral otro. Ias siombras se haráln por Setionbre y Octubre.

Para el plantio lus palajes más allecualus son los que están situalos entre sol 5 sombra, el terrenu nuo le couvione hat de ser férril, aronuso, sustanciusu, fresco. lijoro y sueltu sin ser lúnedo ui estéril, los deuns todos lo son perjudiciales. La éjuca más opultulal lialia verificar el plantio es por Octubre y Noviember ja-

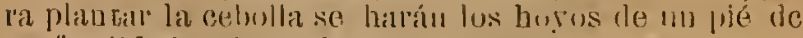

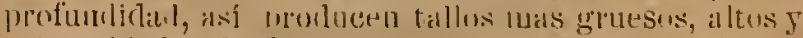
mits publiules de flores: se verentican e.tus platutios de dus mitueras, ó plabtadolus en una livea no interum- 
pida, ó en golnes de cinco á seis cebollas en cada circuito de un pié de diámetro, donde se ponen bastante separadas para que tengan espucio en que ensanchar.

El cultiro que lequicren se reiluce il la limpieza te las plantas extrañas, repitiendola dus ó tres veces en la primareri, los riegos son precisos, pero con modoracion: convieneá los tallos ponerles untores mara que no se doblen con el peso do las flores: luego gue se han pasado y marchitado liss flores se cortarán todos sus tallos, reservando tan sulamente los que se destinen frara la recoleccion de simiente.

\section{Jacinto del Perí.}

En todo es igual al anterior de modo quo escusado es hacer repeticiones que no sean prurcchosas.

\section{Dol Tulipan.}

Isa flor de esta especie os solitaria, grande, derecha y términal, de color amarillo, natianjado, encarnado cun los bordes de los pótalos blaucos, abjgarrados do blaneo 5 morado, ceresa, fuego y pardo oscuro; son bastante olorosas, 8 se dividen en tempranos, taldíos F dobles: el tallo es derecho, rollizo y de clos piés de ilto con tres hojas alternas, que lo onvainan, gruesas, awado lanceoladas, canaladas con los márgenes ondeadas, de nueve á doce redos do largo y cuatro dedos de ancbo y son tanto más pequeñas cuanto se hallan más elevadas sobre el tallo: la raiz es uua cebolia ó bulbo casi awado compuesto do unehas túnicas grueas 5 carnosas. 
Siemura, plantio y cullivo.

Esta flor se multiplicil por el anmento de sus cebollas $\mathrm{y}$ por sus semilias, pur estc último métudo es el

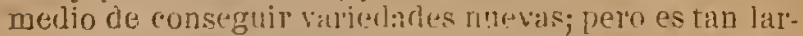
go o fastidioso, que solauente se practica por algun aficionado; para ejecutar las sienbras se dispondrí del mismo modo que se lijo para los jacintus, whiatolo une tierra suave y lijela rominutesta de mai parte do arena gorda de rio, usa de mintillo muy cousuniclo y dos cle tierra de soto muy lijer", todo muy bien levuelto 5 desmenuzulo: la siembra se cjecutalá í últimos de Agosto 5 en Setiembre esparramando la se.nilla cou igualdad y no mus esiesa; se cumprin las simientes con el girneso de un ledo con la tierra compuestas 5 . luego se regari cun refintera moderadamente; il la suGunda veriluma se echatra otia tambla ile tierla compuesta del grueso le un diedo: se dejan jor dos ó lres años sin sical las celobllas del semillel'o, en cura época se furtalecen 5 elựuesan 5 hasta el cuarto año no vienen á mnnifestar lia flor y eso tampoco en su color rerdirleso.

Prevaleren en las ticras de miga, ligeras, suares, mug esponjosizs, que timen fonrlo suliciente? no ostancin las aguas; y en lats que partic:jan de arenosis

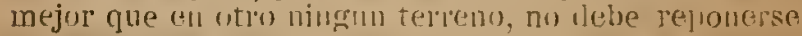
en un terreno a ménos que mo havan pasirlo ruatro ó cinco añus desile que se renris en ele cal iro de tichar flom, coll esto solo se listan lats flures en mis realer y primor. Los terrenos destinndos al en'tiro del unlipan se lahrarán con el nayou emero. El tiempo de ha. cer los plantios es desdo últimos do setierubre hasta 
mediados ilo Noriembre, pero algunos suelen coniuuarlats hastil Eneru: los dias secus y templados sun us más apropósito gatia rerilicarios; la rielra uleber hallarso igualulente preparada 5 sin hetuasiadn bume. lad; la rractica coluun es abrir coll una cua gruesa lugos capaces le admitir cada cebola, y a fin de quo 10 quede esta on hucco se rierte ez el fundo lel hoso l t tiurra suticieate nara que siente bien; deben quedar $(\cdot$, tertadas pur encina del apice de seis á ocho dedus: (.) métudo de plantra th Zanjillas es mís eficaz que of anterior y queda reducido á ibrir unus surcus de ocho 6 diez dedos de profundidad yor medio del almocafre: colucadas las cebulias á la distancia arreglada se cubren con la tiorra que se saca de la zanjilla inmediata, que doberí yroporciubin'se á medio pié de dis. tancia, y asi se cuntinúa hasta que queda concluido ol plautio.

El cultiru so reduce it desbiker lins costras de la superticie de la tielra en caso ie que se halle furmado antes de brotar las plantas furm, uperitcion que so hace con el almorlate: lits unins jerbas deben destruirse ántos que adquirir foerzi, on cuanto al ropartimiento del riegres se suministiaráu sulimente coavdo están creciend. I mirutras perwaceen en flor, mas despuus no deben regaree.

\section{Recolccion re simicntes y raiccs.}

Los tuiphaes undres quo so eijian frara la recolecciun de simente deber problucir la fior bien proporcionalia, los callos uhe vadus y gruestas, los coloros sin mezela, pero briilantes, los petalus do bastanto cunsis. teucia, anchos j redondos a su cima $y$ en fill deben 
reunir todas las cualidades cie un tulipan perfecto: las simientes se dejalin uadurar con toda perfeccion, 5 en abriénduse las cajas se cortarán con palte dol tallo y se gualdarán etl paraje ventilarlo y sceo.

Pata lit recoleccion do las cebollas se dejan sin sa. car pol espacio de tress años y pasado este tiempo, so sacan con el azadon; la époci de verificarla es cuando hau perdido el jugo las hojas $y$ tallos y se hallan do color seca, se extienden por quince dias on ua apo. sento seco y rentilado, y se limpian de tudas las túni. cas sueltas luego que están bien enjutas.

\section{Tulipanes en el tocador y aposentos.}

Se preden tener estas flores nacidas en el wismo tocador logándolo con mucha facilidat y exponiendo las cebollas on cebolleras llenas de agna: debe proporcionarse la cebolla al hueco de la cebollera de maneral que entre bolgadamente pero sin riesgo de hundirse, y tucaudo al agua por la parte interior del sulbo; para lo cual so cojo agua de lluvia ó de rio que son las mejores, se colocariu en los cuartos cerea cle la ventana con lo que so obtend'ri una flor hermosa y olorosa que perfumará bastante.

\section{De la prililaria ó tablero de damas.}

Esta es uria clase de flor muy rreciosa, por hallarse los pétalus con cuadritos simétricos blaneus 6 amarillos, y rojizos $\delta$ encarnados mas ó mónos oscuros, lo mizmo que un tablero de damas: es nativa de los Pirineos, pero yil se halla en torlos los jardines, florece por Abril; el tallo, quo no nace del centro de 
li cebolla como en easi tulas las demis plantas libi:i-

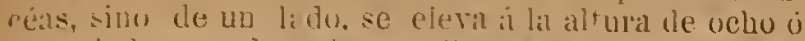

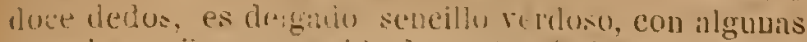
manchas rejizas yo restide de ellatw ó cinco hojis sen.

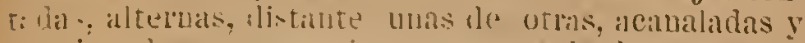

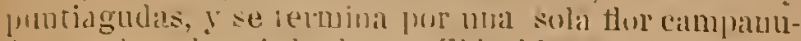
d. : produce lis ririz bubsas, sólida, bliuquecina, relourdir 5 algo comprimida, nel tamiũo to nna nuez.

Siembra plantio, culturo y recoleccion de semilla.

Én un todo lo mismo que el tuiipan rénse esto para lo gjue se quierin.

\section{Del Narciso.}

Esta flor es de varios colores I sumblincos, nitranjadus, abigrarralos, amilillo ge campanilla color do limull o.

Lus especies de nuriso se reducen it tres: la jumera clise que se forma de los que lil csputa coutione, muchas flores; como son el mareiso maluejo, el criental y el olureso: la segrudal los marcisus ue flor solitaria como el fialso naresso, el incotrpin rable y el poético; y la tercera los junquillos. Todus prorlneen una cebulla ó bulbo, awado mas ó umenos glitodes con sus túnicas

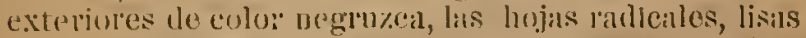
en forma re estuque g mas ó menos litrgats y estrebebis

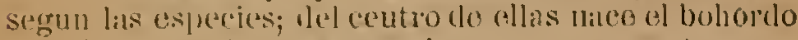

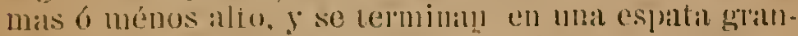
de y' lo erolor de linjal seeal, ghe se alro por un liselo, y salen alo cila mona ú mas flores, mas ó menos grande y de diversus colures. 
Siemura, plantio, cultivo y recoleccion de semilla.

El mismo nétorlo que so ha explicado para ul jacinto so practicaria cun el uarciso en tudas slis partes.

Je la vara de José ó nardo aloroso.

Las flores le esfeso hallin colocados por un órden alterav eu la exrremidal del tallo, son blancas 8 muy olorosis: las flures empiezan at lesenvolverse [pol' Julio desde la ba:e de la esjiga hacia su ciuna 5 siguen florecieute cerca de dus meses. Las lojias r'ndicalos sou largas, augostus, acanaladas y puntiagudas, el tallo so levanta á la altura de trees ó cuarro ó unás jiés y está joblado con algunas hojas que lo euvainan, y sou tauto más cortas cuanto más apartadas de su base. Tíene una raiz bulbusa, tunicada casi redonda y algo comprimida, y colocada subre un tubérculo casi redondo. Las variedicles que se conocen de esta planta son, la sencilla ó comun, la de flor dublc, la de hoja jaspeada, y la lle flui pequễa, y todas se propagan por inedio de sus bulbos ó cebollas.

Siembra, plantío, cullivo y recoleccion de semillas.

Respccto át la siembra se bace lo wismo que de jacinto.

El tiempo adccuado para ejecutar cl plantío es por Qctubre $\$$ Noriembre. 
De la azucena y el martagon.

Las thores de la azurena son do colup hlancas, cribr

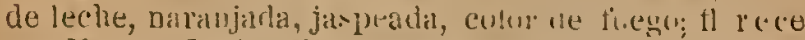

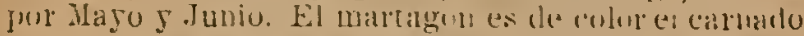

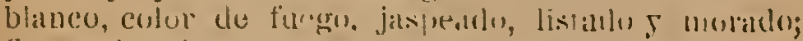

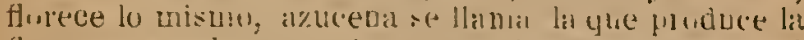

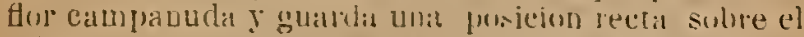

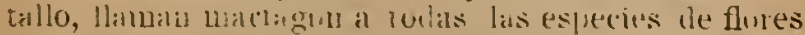

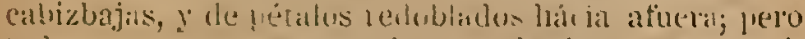

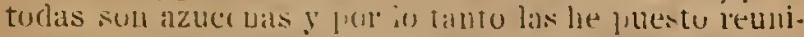

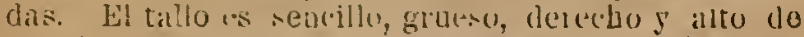
tles á cuatro piés: las bujils radicales sun uuby largas, oblongas, ondeadus, putiagudis y entelas, y las dol tallo esparcidas, uny numerosas, sentadas, y tanto mis cortas cuanto mas iumediatas á las tores, se projaga con mucha facilidad 5 son muy hermosis 5 fragintes. La laiz do estas plantas $\pm s$ bulbusin, 5 comjllesta de un uúmero considerablo de casquilus caruosos.

\section{Siembra plantio y cultivo}

Generalmentu se disponen semilleros para obtener variedades nueras do algun mérito, pues las especies jardineras son meras rariedades que por rarisima casuilliad propagan sus diferencian por semillas: ol método mas conreniente paria los scuilleros es como se esplicó para los jacintos: (1 tiempo do veriticarlo es por $\Lambda$ gosto y Setiembre, echíndolo lo cubiorta á la simiento uaos tres dedos escasus.

Los terrenos para el plantío do las azucenas ban do 
ser de miga y sustanciosos, pero suaves $\mathrm{y}$ algun tantn ligeros, libres de encharcar'se $y$ deben gozar de una posicion entre sul y sombril, penrque el demasialo sol las perjudica, la azucena namnjarla y algunas ciastas dt martagonés mevalecen debijo de las sombras de los árboles: se plantaln por Agusto, Setiembre y Octubre á la profuudidad do ocho dedus.

\section{Recoleccion de simiente, raices y enemigos.}

Se escogrerán para simiente las plantas mas sa?urla. bles, de mas vigor 5 de tlores rle fondo oscuro y colores enceudidus y vivos que rleberán ocupar los jaraies vcntilaslos, dondo madurarác las simientes cou mas perfeccion.

No su pasarú á la recolcccion de las raices ó cebo. llas de la azucena $\square$ martagonés á menos de que no so hallen ya sin jugo los tallus y pasados tres 6 mas iños despues del plantío y á pesar' te que puedan aguantar sin lesion fuela de tiel'ra por tres ó cuatro meses, es mas conveniente plantarlas sin dilacion en terrenos que deberán estar ya rrevenidos para este fin. Por Agustu se puesleu ya sacar las cebollas 5 para guardalliks deberau estar perfectamente limpias de tierra $\mathrm{y}$ bieu elijutas.

\section{Ine los lirios.}

Son muchas las especies de lílios que se hallan descritas en las ublas de botánica: unos tieneu lins latices tuberosas y otros bulbosas; $y^{*}$ torlos cllos puerleu servir para plantas de adorno de los jardines porque proulucen flores muy vistosas y de wucho mérito y hermusura, tanto por su extraúeza como por la variedad d 
matices $y$ colores con qque las aromó la naturaleza. Las hojas de los lirios son en forma do espalas mas ó menus largis y anchas seyulits especies; ha flores son tambien mas ó menos grandes y lo diversos colores como blancas, azules, amatilis, encarnalas, violeta abigarradas y manchadits, $y$ por lo tanto ponilú las especies en particnlar, para luego poner su cultivo y do más en genet’al.

\section{Lirio cnano.}

Las flores de esta cspecie son de color de porcelana, blancas, azules, uscur'ts y encaruadas; los tailos se ele. van á tres ó cuatro dedos de altura, son was cortos, lits hojats $y$ cadal uno sostiene una sola Hor bastante grande; hi raiz es tuberosa, blanz̧uecina, gruesa, mudosil, profundiza poco y despide un olor agraclable; florece por Mar'zo y $A$ bi il.

\section{Livio de Persia.}

La hermosura de las flores do esta planta, el color aprerlaro tinturalo de azul, el florecer tan tempmo en la primavera, y el olor agradable que despicle, la hacen muy apreciable, y es uno de lus principales adornos en aquella estateion temprana; floreco por Febrero $y$ Marzo antes de mostrar sus hojas quo son acinaladas: aleznadas y mas larrats quo el tallo; ésto erece de cincuá scis dedos te altura y sustiene ma sola flor: produco la rai\%, bulbosa, oblonga y blauea.

\section{Lirio b!alboso comun.}

La flor de este lírio por lo comun son dos bion gran- 
des de un hermoso color azul uscuro, warece dle barbas, y eo su lugar se hallan seũaladis lits estremidades do los tres pétalos caidos hácia fuera con una lista de culor de caña: ol tallu es juguso y jecjueño, las hojas acanaladas, oblungas, termididals cu puuca; prouluce la raiz oulbusa, grande y caruusa.

\section{Lirio de piel de tígre,}

Es una flor hermosa mas grandc que las demás es. pecies conocidils, de color do plomo, marizsda con líneus negruzcas, violadas y grises, carece de olor y flo. rece en Majo; las hojas anchas eu formit do espada, los tallos crecen hasta cerca de dos pjés te altura, rollizos, uudosos, corouados por und sola fior: la raiz tuberosa, gruesa y calnosa.

\section{Lírio turco.}

Las fiores de éste son amarillas salpicadas cou mau. chas uaranjaclas $y$ negruzcas; florece por Julio y Agus. to: sus lujas altercan scmejautes á la de lus líios, grandes, anchas, envainan al tallo, que es vucloso, gruesu y de tres piés de alto, produce su raiz bulbosa y carnosa.

\section{Ifrio chrdeno, azotado y de Filorencia.}

Estos y algunas otras especies que se cultiran en los jardines, se umiten por uo aumentar descripeiones, mayormento cuando todas se refieren su cultiro al modo que so esplica aqui. 
Siembra, plantio y cultivo,

Las ziembras de los lírus se egecutaríu por $\Delta$ gosto $r$ Sutiemin ó mo la primirera $y$ aunque es método inny int) y mas engurenso que ia multiplicacion por celobilas o hijuelus, suele no obstante ponerse en práctica, y así se proungi con mucha abundancia; estas simmbras se reriticarán on cejones $\delta$ en eras al descamfrirlo, pero siempre será on los primeros: pari lo cual sp foreparará una me\%cla de una parte de tierra vírgen, dos parter re légamo ó fango, una parte de mantillo y media de arema todo bien mezolado r rerueltu: desjues de hochas las sienbras no exigen los somilleres mas culdato que suministrar los riegos con moderacions ell lus princinon, luego que ya crecen se los va aumentamolo graduelmente; debcri de quorlar á distancia unis de otras de ocho derlos y lak demais se arrancan; lucgo stue han takado la primera verdula, rept. tienclo csta uperacion igualmento al siguiente año: es-

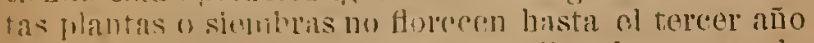
f) r lo quie permauecerín en è semillero hasta pasulo mis timentmo.

[ala plantio las castas enanas requieron terenos

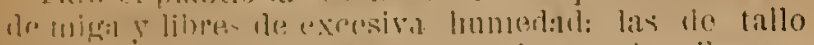

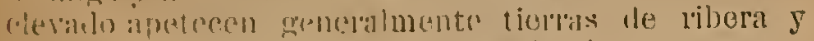

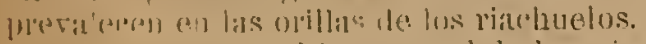

No cxigen mas cultiso que al de las riegos que so

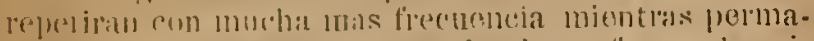

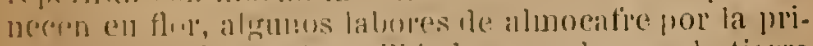
mal verat son de mucha utilidiul para almecill la tierra y refrescar lia plantil, 5 por ol otoño es bueno ammen. 
tar de uno á dos derdos la capa quo sirve de cubierta á las raices, arrancando las plantas estrañas.

\section{Recoleccion de simientes y raices.}

Se recogerín para simiente las plantas de tallo grne. so, de flor anchil y de colores vivos, y en las castas las de especie listada que tengan interpulados los colores con mas simetría; uo se pascará á la recoleccion de las semillas á tuenos que no pardeeu y empiecen á abrirse las cajas; en esta disposicion se tenderán sobre lienzos a la sombra para que acaben de madurar, y luego so conservarán en botellas 6 ou cajas Je hoja de lata para que no cojan humedad.

A cada tres ó cuatro años se arrancan las raíces para partir los casquitos é hijuelos que han produciclo, con los que sc hacen nuevos plantios: pueden consel:varse estas raíces fucra de tier'á por catio ó cinco meses, aunque siempre es wucho mas acertado replantarlas inmeditatamente. En el caso de guardarse las raíces so plactirá la recoleccion cuando ol terreno se lalle sin humerlad y ántess sc dejarán orear á la sombra, y se limpiarán perfectimente de toda tierra, y de todo podrido, mahullado y dañado que se perciba en ellas: en este estado so guardarín empapeladas, saspendidas del techo, $\mathrm{y}$ mucho mejor puestas por tandas entre arena ou cajoucs anchos freveuidos á este efecto.

\section{Del pamporeino ó solitariu.}

Estas Hores son solitarias, blancas, encarnadas y la boca del tubo es violada ó purpurina, florecen unas eu 
la primarera $y$ otras en el otoño: las hojas varian mucho en esta planta $r$ son mas ó menos acorazonadas ó en alaharilas, redonciearlas, clentadas, de un rerde os. curo con varias maachas blanquecinas 6 amarillenta ell su haz,, rujiza en el enrés: de cada una de las ye miss de la laiz brotan uno ó dos y algunas veces mis tallos muy cortos rollizos. limpiños 5 do ocho á doco derlos de largo; su raiz es tuberosa, casi globosa aplastalia nagruzca al asterfor y blanca por leutro, arroja murbas hebrillas que naceu sin órden de su superficie.

Siembra, cultivo y recoleccion de scmilla.

Se eqecuta lia siembra del parporcino por la primarera y ul utoño, dol mismo morlo que la de los anémones, siendu la semillia de burma cualidad g bien sazomalil, se esplarran:a algo clara, de manera, que las plantils se hallen al tiompo lo nacer á la distancia de umo is dos derlos.

lil culriro de esta planta queda reducido á suministoar algunals labores de almocafre por el otoño 5 primarcerid, clesarraigando torla yorba extraña.

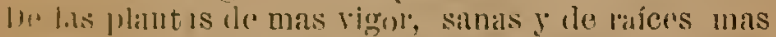
Eritesats, se delse reroger la suniente, $y$ á menos de

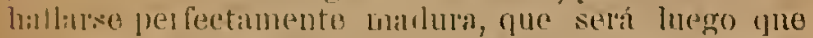
lal ("ajjas empireen a abrirse: antes de ghardarlis delun estal enteramente secis.

\section{Del arafian.}

los sou las esperies matmules do azafran y quo so enltiran en los jardines; el de prinalvera puo sus flores sun grandes, de colur entre lila do rosa, con el ton- 
do blanco o enteramente amarillas; 5 el de otoño que sus flores son encaruadas, moralas, blancas aperladas cenicientas, azuladas, amarillas, anteadas color̈ do leche y caña; las hojas ilel primero son lineales unu es. trechas, nuutiagudas, te seis á ocho dedos de largo y de color verde reluciente con una raya blanca longitudinal en su centro todas las hojas estíll eontenilas por su base dentro do una tú uica membranosa $y$ trasparente, y de su centro nacen mana 6 dos Hores, las que manifiesta iuvariablemente por Marzo y Abril: el de otoño ó segundo por Octubre siemire florece, producen una raiz bulbosa, sólida, redouda, pequ'ña $\mathrm{y}$ cubierta do una túnica parausca en forma de reil, de su base salen mucbas raicillas blancas $y$ en su parte superior nacen las hojas radicales,

NO'TA.-Por convenir un mism: cultivo á las siguiontes cebollas de flor, á fin de ol)viar repeticioues las colocaré en el siguicnte capítulo.

De la villorita ó quila meriondas.

Se cultivan en los jardines unchas rariedades te estas plintas y se prefier'cu las tlores dobles; lias bay encarnadus, color de losa, blancas de color de ciñu, floreco ilesde último do Setiembre basta Octubre pro. duce sus hojas por Diciembre y no manifiesta su frutu loastr Febrero 6 Marzo; su raiz es bulbosa, sólida, envuelta con varias túnicas negruzcas, awada y de dos á tres dedos de diámetro; de ella nacen sus hojas radicales en forma de embudo, y bastante scmejante a la del azafran; los bulb.ss que han florecido una vez pere. cen g en su lugar naceu otros nuevos cou los que se multiplican las plautas. 
Fioleta dientc de peiro.

El color de sus flores son inurado, epcarpado, color de fuego $\mathrm{I}$ blanco; sut hojas radicales atrada, señalalas con planchas rojizas $y$ biauqueciuas sobro an fondo revde claro 5 unius gor su bise en un tubo largo que uace do la idaiz; de su ceuiro sale el tállo ó bohurdo rojizo I lampiño do cuatro á cinco dedos de larro, que sustieue una sola flor cabizbaji; su raiz es turberusa, varnosa, blapquecina, oblonga $\square$ de la figura de us diente de perxo, de clunde ha tomado el nombre. St conocen dos variedades $y$ prevalecea en los terrenos frescos, algo húmedus y sumbrios.

\section{Campanillas de inciemo.}

Se conoce uva rariedad de Hor doble que se adopta para el cultivo de los jardines, de color blauco cou !nals maurehas rerles y viceversa: florece on Fubrero, sus bojas radicales suu lineales, li:mpiūas, do unos seis dedos de largo $y$ tres líneas cie ancho, el bohordo ó tallo algo más larga yue las hojas, oxtraido y terminado por upa espata oblonga con algunns ravas vordes que se abro por un larlo y encierra el piececillo Jelgado que sostiene uha solit flor cabizbaja: su raizes bulbosa, redouda, del tamaño de nna avellana; de su parto superior nace una tícica menbranosa, blanquecina y trasparento.

Campanillas de primavera.

Las flores de esta planta soi muy parecidas í las de vorano, pero se diferenciu esoncialmente de esta, por tener sus colores muy diversos y su figura, por sus 
tres hojas radicales que son más angostas, aunque más auchas que la auterior, el hohordo es el doblo inís largo que las hojas, terminado por su espada re1dusa, que se abre pol un lado g encierma uni sola flor, y á veres dos, cabizhaja y olurosa, sustenila por un jieceillo delgado; Horece por Marzo g provalece en terlenos frescos, húmedos y sombrios.

\section{Cumpanilla de verano.}

Esta florece por $\Lambda$ bril y Milyo, y su bohordo que es de mis le un pié de alto y lleva cinco ó nueve flores, produco su rai\% bulbosa de ro:lyor tamaño, y sus bojkis mús anchas y mayores que las de la especie antérior.

\section{Siembra, planlio y cultivo.}

El mismo métorio que couriene para la siembra de los jacintos, so puede seguir lara torlas estas especies mencionadas, apesar que es muy lento y solo so prac. tica cuando se desean nuevas variedados; las siembras do la violeta pueden hacerse tambien en Fubrero, y en mezcla de tierra do sustancia y de miga.

Los bulbitos de estas plantas se plantarín por gol. pos in fin de que al tiempo do dar las flores sobresalgan cou su abundancia y hagau buen efecto en cala golpe so colocan sois ú ocho cebollas algo sepaliadas, it la profundidad de cuatio dotos sobre el ápico del bulbu; provalecen mejol en los parajes sombifos, y aun debijo de la inmediata sombra de los árjoles no reciben al inás leve daño, y requieren para su cultivo las tierriss sustanciosas y algo húmedas: ol terreno se ilunalia y labrarí con la milyor perfocclon, beneficiándolo cun mantillo y ai hubiosen servido on alguua produceion do hortaliza, sorá tanto más apropósito para esto efec. 
to. Las cebullas de cada casta se plantariu jumias ó bien se interpolarí de numera que las viriedacles y diversidales de colores agriducom mís bien is la risiat. El

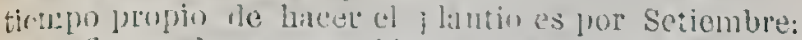

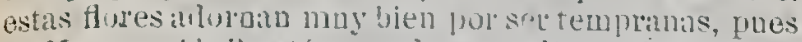
en Jarzo y Alril estan ya desmrueltas y hermosean en afuella estacion con su dirersidal de colotes.

Los plantíos de las violetas se harab pur abril y Mayo compartiendo las rolices muleipliculas El de la ri. Ilorita se hará en Julio, Agestu y Suticuble.

El cultivo de estits plantits so lednce á limpiarlas do rerba y los riegos se summistralan cuatuclo ellas las necesiteo.

\section{fiecoleccion de simientes y semillus.}

Sin embargo do quo generalmente no se disponen senilletos paria la multiplicancion do estis plantas, ou dondo uo son inny cumunes y se tesean tener nuovas castals y variedades, se seprarinin algunos piés de aquellas más lirondosas y do flores mas vistosas, grindes y do colores viros, no dobiendo cojer las semillats at ménos que no so hallen on bnena disposicion y eate. ramonte maduras.

Pitra las raices ú cebullas en tojan sin sacar jor ospacio de tres ú cuatro años, pasalos estos, para sacarlas han de estar en la disposicion que ya se tione ropetido y de hallarse lir tierral sucal al tiempo de lia rocoleccion.

\section{Flor de lis.}

Fsta consta de ma flor y ál reces de dos, de color de tuogo, con venas longitudinides, de color do prípura oscuro y como aterciopelada, grande y muy hermo- 
sa; el tallo nace de un lado de las hojas; es grueso, algi) a plistado, rojizo y se termina por la espada encar. nacla de dos piezas, yue se abre lateralmente en dondo encierya la flor, iroduce una cobolla gruesa, las lurjas anchas, largas $y$ de consistencia dura; florece desulo Marzo hasta Setiembre.

\section{Hermosa Raguel.}

Ista contiene de seis a diez, Hores encarnadas que parece están matizadas de mumas le uro, cuando le di ol sol, sosteridas por su piecécillo desiguales de una ó dos puigadas de largo, 6 insortos torlos en un mismo lunto: liss hojas de un verde usenro y brillante de po1:0 más do media pulgada d" ancho; $y$ de seis á wrh" pulgadis do largo, terminadis por tina punta obtuka, $\checkmark$ mas corta que el bohordo, que es de mats de un pie de alto, la espada es membrinosa, rojiza, de dos pierais en donde eucierra las tures; su l'yiz es bulbosa, gruesa awada; llorece de Setiembre basta Diciembre,

Se conocen otras muchas especies de este gúberu. todas muy vistosas y de mucho adorno, couno son: hi azucena de Méjico, la bella dama, la azucela listada, í tolas conviene el mismo cultivo.

\section{Siembra, plantio y cullivo.}

So hacen semilleros para la propagacion de ustas plantas, para la cual la siombra se verificarí eu cajones portátiles en proporcion al múmero de plantals que so intenta obtener por este métoda; la tierra so inullil'í perfectamente arreglando una mezcla de und parte do tierra virgen, otra de mantillo de dos años, y dos partes arena gorda de rio: so esparramará la simiente con igualdad sobre la superticio allanada, y se cubrirá 
con tuva capa del grueso de uedio decio; estas siembras se harán en Agusur y Setrembre ó en Fubrero y Halzo: los riegos sub necesillios para su germinacion y asi mismo lia limpiesa de plautas extraúas para su arraigo. No Horecer estas plantas hasta las tres vorduras despues de su sirubra, $y$ for lo tanto conrieno dejarlas en los semillıros hastia los tres años y pasado hatcer el plantio.

El tiempo del pliutiu es por'Setiembre, Octubro INoriemiore, se multiplicau todas estas plantas por los bijuelos que producen las cebollas madres ó priucipales.

Pala el cultiro la limpieza do plantas extrañas es de la mayor importanchi, los riegus deberin ser escasos, y solo en el tiempo de la flor aprovechan para que so prolongue su duracion fiur algunos dias $y$ so consurvo cun la vireza de colores que lo es propia.

\section{Recoleccion de cebollas.}

1 los tres aũos se sacarńn do tiorta las cobollias st apartará la prolo que hilya doamuento para muevos plantíos, $y$ despmes de bien limpias y onjutas so pueden guaidar empapeladis algunos moses on parajo seco y ventilado.

El mismo cultivo exijen las plantas siguiontes "fli" lara no abundar en deseripeiones solamente citaré por sus nombres, por s acaso alguno quisicra cultivillis,

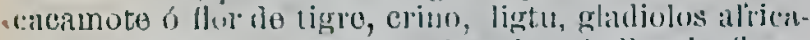
nos, pauclateins y otras esperites ife cebollas de flowe's delicalas y muy mreciosis.

\section{SECCION CUARTA.}

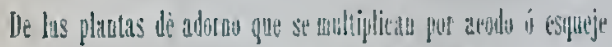

Del clruel y de la clavellina.

El clavel y la clavellina con que se adornan y hermu 


\section{$-51-$}

sean los judines y las muchis variedades que se tie. neu son hijas de una misma mane ó tipo eomun y lan sido obtonidas pol semillats de la planta silvestre. Se rlistingue cou uombre cle clareles las cisias que pio. ducen sus tlores doblos, glamico, j cuyos calices es ne. cesario ayuda: it fin de que los jétillos so extiendan con simecila y arreglo, esto ('s, so intronluce entre el caliz y los pétalos uu circulo de papol frecte, cintulini 6 aaipe que mantiene lit flos hirn abierta y exrendida. Hay clareles do un solu color ya seál blanco, color de caña, de leche, oncirmato, mulablo, achocolatalo, ca. nelo, color de rosa, "le singule, de fuego y otrus más ó ménos subidos, lus hay listinios layados, cou uatices de dirersos colores, y finilnente, moteidos, discipli. nados ó salpicalos; el térumo medio que puede hacerse durall por lo comun todia cista de clavel en su mayor vigor y herraveura es el de doce añus, pasado este tiempo comievza á deterioral'se $y$ decatr. Las más reces sucede rue al segundo ú tercer año se atchica ol ta. maño de la flor disuruusento su disco á cada nuevo plantio: tambieu acuntece no pocas reces que se chañn las plantals y los entra th mal epidénico que anjouila de una vez las castas. Pur simionte do dat vellinas es cojidas 5 bicn dubles, y de algunas constas de clavel que granan, se cousignen todos los años castas nueras de clavel: en los cintelos de clavelliuas se señalan aquellas castas reventonas le mís pétalos para acodar, y sc logran nuovas aspecies alleciables que signen perpeturidose por ácodo y csquejes.

Lats cualidares que deben aeomprañar á una clavelli. na jrata considerarla de bórito, son: los rallus ó conyas gruusas, rectids y cleviulas, lus cilices soran alghun tauto oblongos, triphulus; y ao deben rurentarse, lat flor graude, compuestia de muchos pétalos auchos, de 
consistoncia carnosa, con sus bordes repiqueteados $\mathrm{y}$ si sun enterus 6 cupas aserrainras sou imperceptibles, son mucho mojoles; jos colores oscuros y enceudidus se aprecian más la simetria y arreglo armunioso y. bien detranination de estos colures es ev lo que se furda la uatyon pereceion do todal clarollian.

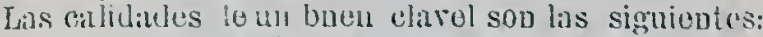
los vastagos ó uil is jugosan, gruesas, rectas y' lo mis

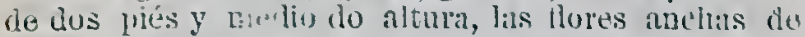
cuatro 6 cinco deilus de dicmotro por lo ménos cobrpue: tos de vumerosos pétalos, arreglados do manera que en ol centro dr la tlot so elorou, algo mis, bien dispuestos siu confinsun por su mucho número, anchos ubtusus i su extremilad, de consistencia carmosib, thteros, los exteriores mayores, disminuyendo on tamilin pregresivamente hacia el centro de la thr; los to I11 color solo, sou apreciables cuando son encendidos, I’isí mismo lo son los de colnr de caña y los blaness siu maucha alguna de otro color: entre los listados son lus mejores los de faja bien mareada allchas pur el borie clel pétalo y angostildas por lias uñas.

\section{Siembras.}

El mono de propagar las plantas de clavel y clarellima es por sus semillas, por sn icodo, y por usqueje, so siembra lit cliveltima on canteros al raso en macotas jy cajones, los canteros deberíb sel de tierra instanciusa ó beneticiada eon tierra vegetal de soto ó virgen, con mantillo bien reperiblo que hilya servido on criaJeros $o$ seunileros de hortalizal, á fici de quo tougat corsumida la aceitud perjudicial gue poseo ustabulo reciente y eaterizo: se eavaran a azadon dosmemzando los terremos $y$ almecaudo la tioria pina guo poedin 


\section{$-56-$}

- brotar las simientes; los puutos mas adecuadus para estas siembras son lus yue guzan uua siluacion entro sol y sombra. Las siemijas primeras y que proporcio. uan plantas mils subresalientes son las que se hacen en Miarzo, en Abril y hasta prinero de Miayo, desde esto últinio mes hasta $A$ gusto pueden lepetirse siemblas sucesivas; pero se ha de teuer presente que las plautas qne se logruu de estos semilleros tardios salen muy endebles, visten mal y produceu escasamente flor; es necesario escoger liz sumilla di propósito de las cistas sobresaliente $y$ doble, desecharido torlas las semillas y semidobles á méuos que alguuas de estas por la es. urañe\%, simetria ó vivéza din los colores prometan en lo sucesivo alguna parichad sobresaliente y digna de cultivo, que enconcos se dejarán permanecer pal‘a recoger sus semillas. Son igualmente necesarios los riegos frectentes con regadera antes de nacel: las siwieutes, de mauera qua coustrven una bumedad y frescula moderacta con lia cual se fomentará la germinacion: á los quince dias 6 tres semanas despues de sembranaz, principian á brotal las senillas y es jlleciso continuar regando con regader: liasta tanto que las plantas tomen más lucremento y al'rigau mejur; luego que latyau crecido las plantas de los semilleros de Abril, á la altura de tres o cuatro dedos se trasilantarid en nile. pos canteros bieu labrados y brueficialos con mantillo muy consumidu: los semilleros gue se lazen desde ne-

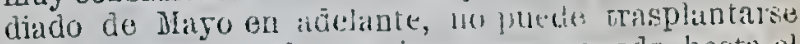
yor no permutif el puen tiempo gue quoda hasta el

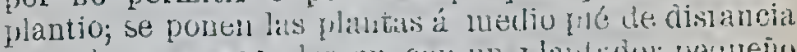

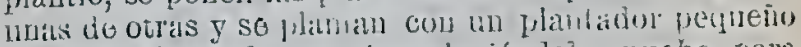
o con el almocifie. Ho introluciéndo?o mucho pal'a gue quede fuera de lierra el sugolio ó crrazon, con el yropjo plintador 6 con la mano, se apretará la tieria 
en la inwediacion de la phusa, para quo quedo bien sujeta y bo harai hneco. En estos criaderos peruanmcea hasta ol incs de octubre que so trajplinten do asionto $\in$ los puntos en que tienen que forecer.

\section{Esquejar.}

Las castas de clavel 5 de clirellina escojidas se propagan prol esqueiés, punias de cugollos, par'a este efecto suelen apartirke algmas nadres del año auterior. que proporcionch a! ghuos engollos, los guc se sepraran de la plautit par il esunejar al paso de que se hillou on buena disfosicion, y hastanto crecido para aprovecharse en esta maniobli del cultivo, igualmente se utilizan los hijuelus of retonos que producen por lat primarela y unono. Luis puntas do los rástagos ýd du. ros para el acodo menten eon aiguma dificultad, no obstante, suclen lograike muchas plautas, Si se piicasen de alguma enteruchal cuntngiosa, so quitariu con tiempo todos los cogulls que pheden dar origen í otres plantas enfernizas en lo sucesivo. En lins castas diriciles de propagar por enquejes deben de conserviare todos las tallos tiernus que nacen próximos a la ratiz, los cusles furman los acrulos mas vigorosos y lírtiles; el tiempu moprio de silcir los esrjucjes as en Sotiembe y octulur. y deste Feb:ro hasta Mayo, bien que siempre yue hay cognilos phede practicirse esta

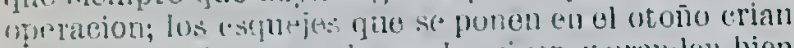
plantas mny fuetes y de muchu vigor, y prendeu bien itungue el tiempe mejor y emamto matran menos es en

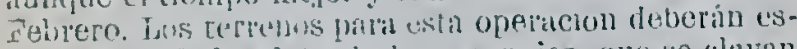
tar resguarinlus del sil; los aspoejes guo so clavan desclo melídos do Marzo, en Abril y Mayo, so ponen on parajess $\Delta^{\prime}$ ubríos, frescos y muy ventilacios y asi 
prosperan mejor. La prictici general para sacar los esquejes, os arrancarlos de la plinuta rasgaimdolos eon lit mano, á fin do que sacqueu algutsis lajitits del vastiggo, porçue así prenden mejol: jero, lesulta do esta practica un perjuicio il las plimtils madres, y auchas voces so picrden pur estal causa $y$ si se desca leservill la plantii madre se cortarán los cogollos mits tiurnus con tijeras ó narajas, $y$ no causalr las llagas ó lagrimales que las perjudica; no se - cortarain on este caso fos tallus tan inuedhatos al vistago, siuo que se dejaráll permanecer los dos uudus interiores de caua uno. y los cogollos se ruitarín con tros, cuatio ó mis uu, dos; por: esta pláćtica, los aquejes igarlan igualunente bien, y' ea lis pliuntas madres quedau lleusis para brotar nuevos cogollos, y isi la planta no deja por esto de anacollas y ser títil pala florecer. Estando como debe restar bien fina la mezcla, se vali clavando los esquejus en lia tier'a hasta el serumdo nuto, toniéndolo eogido con Ios decios, el índice y ul pulgall de la mano izquierda, y con la derechia so micisa con el plantador al todedor del esqueje í fin de que no halga hneco y quedo bien apretada la tierı: procurando pouerlos á la distancia de tres ó euatro derlos unos de otros: ántes do clavar los esquejes, so regarí moderadamente para que encuentreu frescura y lumedad, y despues de clavados, so repetirín los ricgos reon alguna frecuencia a fic de mantener una humedad continuada: en llegando la primarera ya los mas de los cogollos están barbados, y se desarrollan los principios de vejetaciou, per lo quo luego que empiecen á subir se les despuntarí espinzará $\delta$ capiaŕa al segundo ó tercer nudo para que multipliquen y amacollen mas abundantes por abajo, arrojen tallos nuevos y produzcan plantas crecidas 5 frondosas para la primavera siguiente. 


\section{Acodar en lierra ó macela.}

lans castits do chavellinas de simiente, que se han lo.

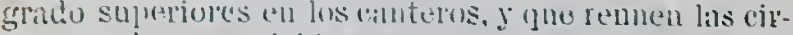

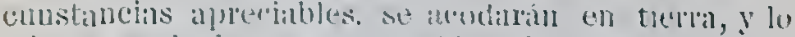
mismo com la de castals collumbia dololes: se forman ("il. sillas ó mblitos do merelis of milltillo muy consumi-

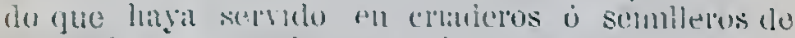

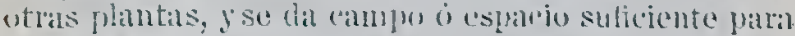

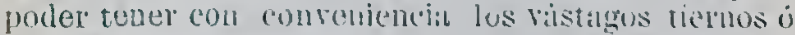

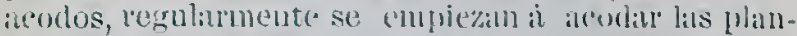

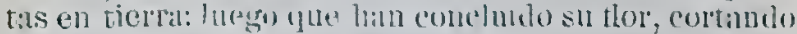
todas las cañas ó talfos pue la hau producilo, y con-

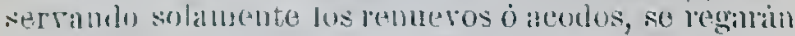

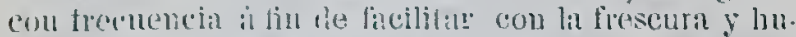

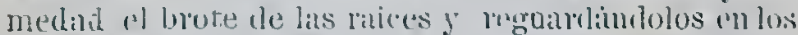
primeros dias (iel rigur del sol.

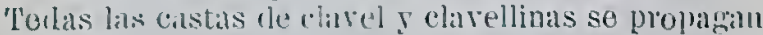

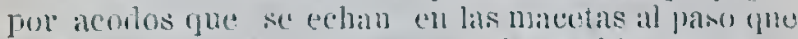
se retifica el desirrollo dre las flures, ó lnegro yuese hatn pitsidu jor Junio, Juliny Agosto cuatudo mas teurprino so acolen, tinto milgor poreion morlucen do raices, y formilu plantas lozinas y de vigol: los ballok mas tiemos y jugrosossou los allecuadus paral esta mat niobra, pues hrotall laires con mals broredal y abutrdancia: la tierta che la maretis se mullití a la profun

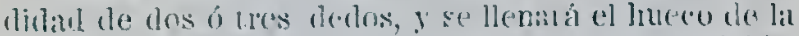

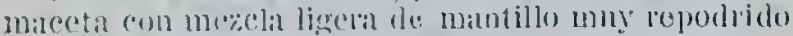

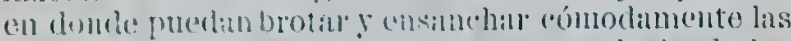

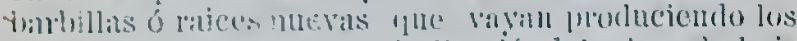

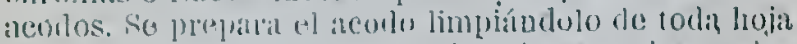

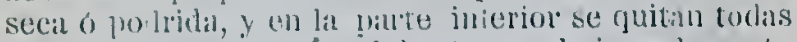
las proximas it lia raik, dojaudo con hojas solamento 
Jos tres ó cuatro nudos superiores: se sostiene con la mano izquierda el rástigo que se julenta acolar, al paso que con la derecha se abre la cisura con nu cor. taplunas, cmpezando por un mulo tierno y jugoso, prolougandula hacia alliba basta el segubuo of tercer vudo on proposcion à la distaucia en yue se hallen colo. cados: este corte no interuará más le lo pue se becesite para ol brote de las raices, la cual peuctrama basta la mitad dol vistago, pr.fudizando progiesi vamente bácia arriba hasta las dus tercelas palres del uitimo nudo doudr telmina: llamase ešolon a la parte de arribi que queda unida í li pliuta madre, 5 es la que prupulciona el jugo al acodo; $y$ lengueta it la interior que quedan desasida $\mathrm{g}$ pendiente del ristago, esta debe quodar perfectamente abiertil y separada del espo. lou, debiendo contener alguna porciou de mautillo en el espancio o hueco: se dobla cun suavidad el ristagó paratoncler en lis rnacota la polvion que debe estal entermada, con mucho tientu, a fiu de no quebl'kl y malograr el acodo, se aterlarán con mezcla muy lijera que couteuga muchi arena: obscrvaudo que el pudo donde se termine la cisul'a ruche somera $y$ casi al rar. so de la tictáa, porque si quedir muterrado mas do un

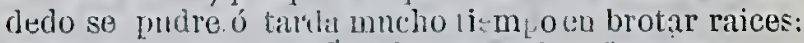
el espolon quedara serlarido de la lungïeta para que la cisura esté bien abiertar, lo guje contrubuge á su mas fácil arringo, introdnciendo biscaute tierra en ellay manteriendo bien sujeta la planta: los acodos se regaráu todas las taries $e n$ los primurus dias do echados, en lo sucesico se suministrariu los riegos por parte de tarde, $\Gamma$ í pesar de que jarezcan enfermizos se regeneratin con prestezi con el beneficio del agua,

\section{Recoleccion de la simiente.}

Sin embargo de que se recoge solamente de lias cla- 
vellinas, hay algunas custis de clarel que las producen, en curo chso nu liehe liesipmrecharse siempre que los estambres y fistilos de lit flor no se couvierten en prétalos, son añtos los clinelts para grimar; pero nunca cuaja la simiente en lus cliareles que la proIuces, eon la facilidit ithuthucia que en las clarellinas. I as especies de clivel que tienen ' largo el cáliz, que se visten meliantumente lo pitilus auchos, dilatados y sin encerrarluris, $r$ que tirmen sn gérmeu perfecto soulus ine deben ilestinarse para la recoleccion de si miente [ol sel uas antos para gramar; exigen los clitvelus mals cuidados que las clarellinas para coadyuvill it la maduracion de las simientes: lleben ruservarse las flores de la bumefiud: y lemediar ell cuanto so puerla you se alman los culicos r revientru por to-

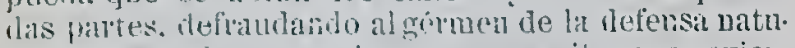

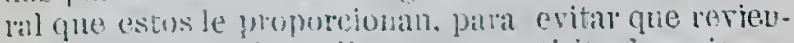
ten deben liatec los callices con una tirita de majagua.

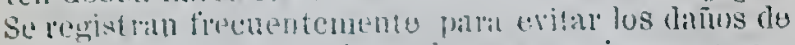

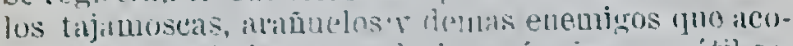

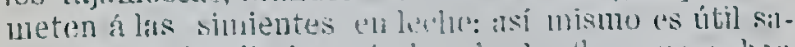

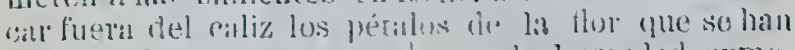

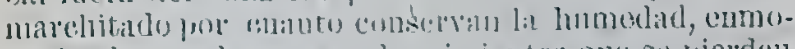

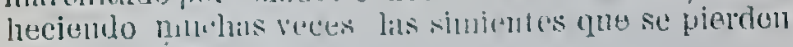
por sulo esial ciatlsil.

Las especies mals jerfecta do darellinas, de colores

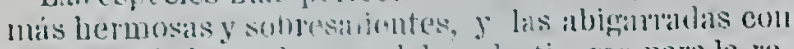

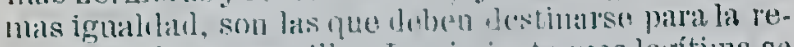

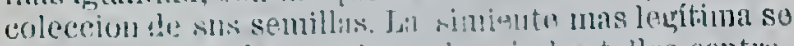

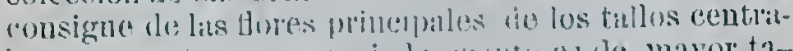

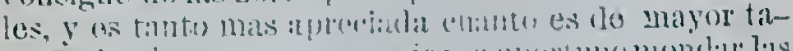

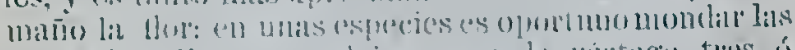

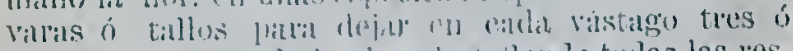
enatro flores, sumbinsiendo y destaliando todas las res- 
tautes: al contrario debe practicarse con aquellascastas que no puerlen impedirse que se rovienten; jues luego que se han cortadó las tores mas sobresalien. tes pard ramilletes se dejarm gratual las más tardias to los vástagos laterales mas endebles, $y$ asi se alcanza semilla buena aunque en pegrreña cantidad: luego que no reciba mas jugi de la plauta y judra li cepa se cottaría ol tallo y sin ernbargo de que generulmente so limpian y guardan las simientes despues rle bieu enjuras, neglas y reluciuntes: es aum masútil mauteuchas dentro de la misma caja liastit que llegue el ticmpo de las siembras, tambrou se dojaráu que ua. durou con toda perfeccio: en la misnua planta y no se cogerán sip tiempo ni autes de que esteu bien nutriuas.

\section{Enemigos perjudicialisimos.}

Los enemigos mas perjudiciales lel clarel son el $t \iota$ jamoscus y arañuelas que cortilu lus tillos, hojas, lietalos y gérmen de la·flor', sum insectos alados, aunque hacen muy poco uso do sus alas: on motando sus eswargos se le debe buscar con toda diligencia para ovital majores daños, pules es tal el ausia de estos insec. tos por los claveles, yno si llergat í ajpodarse de una clavelina concluyen con ella en pocos dias: dichos insectos hragen do la luz del dia, sus daños lo hacon logularmente de noche, y so esconden al amauecer en los parajes frescos y somibríos, debajo tlu las hojas, entre la corteza do los írboles, debajo do las piedras, y aun on las rondijas de las paredes: estos ineectos se lesturuyen colocindo rañutos bien de caña ó do papel, triapos uojiulos ó yerva y ojas húmedins on las inmediaciones de las plantas ó tiestos en doudo se aclvier- 
te su daũo, alli se gunrecen y recogen da la renita del dia, s se matan con faciliulad. Los puigones negros 5 rerdes intixionau las extremidades iucas del clavel, y en matricular so suarecon en la parte bijja del cáliz ren la hiz inferiol de las hrijas nuevis, que roen y iastiman con mucho perjuicio: se multiplicau con norable rapirifz, por lo que doben lestruirso al paso que se eucuobtren, y paria más eritit sus danos, so haban con una booha ó plunil suaro las mitis con ma in. fucionde tabaco ó bien cundo a ann conserva lis planta el lucio, se estralimario polvos de tabaco con lo

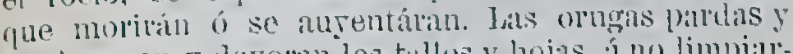
revies roen $y$ legolian los tallos y hojis, á no limpiallse frontamente, dentro lo estis silivizals. so encolitratrín gualecirlas, ó debajo do algua lioja ó robolde de los tiestos, londe se recojen jol el dia para volvel á Sulil de mocho á sus correlias. hos ratumes, las lor-

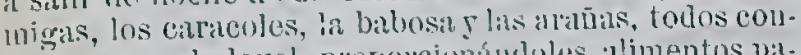
ra sil nutrieion con perjuicio del fleitsta

\section{Clavel coronado ó clavellina diz gluma.}

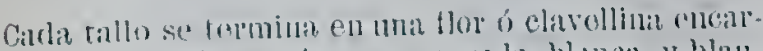

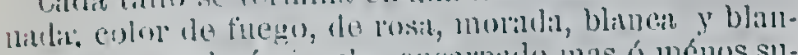

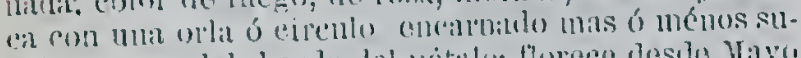

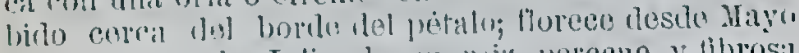

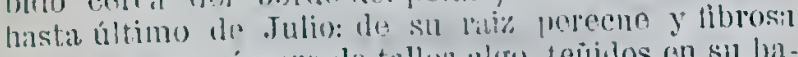

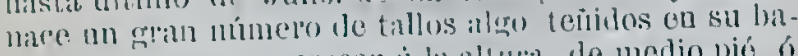
se y rambsos, que erocen it la alluria lo modio pió 6

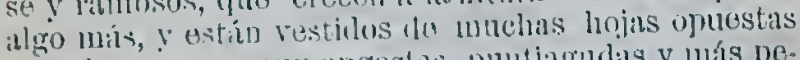
do color gillzo, muy angostas, puntiagurlas y más pegueñas guo las radicilles. 


\section{Siembras.}

Se logran la simiente de las castas seucillas y semidobles, por las une se propaga la planta y sus siem. bras so hacen eu los mismus tiempos $y$ con las mis. mas ad vertencias que las clavellinas. Se trasplantan do los semilleros á los criaderos luego que bayan pro. ducido seis hojitas, la distancia á q̣ue se han de poner será de medio pié en elas sombríns de tierra lijera y bien labrada I teniendo los misinos cuilados que so dijo eu las clavelinas,

\section{Esquejar y acodar.}

Mnltiplicándose por sirniente las especies sencillas y semidobles con notable aumeuto y facilidarl, las dobles eni tudo solamente se propagan por uedio del esqueje, el medio $\mathrm{g}$ mejor tiempo de practicar cou acierto esta operacion es a altimo le Marzo y en todo Abril las demás operaciones perteneciontes al método de clavel, apretar, regar J liérar los esquejes so consultará el atículo do las clavellinas. Prende muy bien y se propraga con facilind por' medio del acodo: esta maniobra de coltivo so haee pol Mayo, Iunio y Julio del misno modo que ya queda esplicado para el clavel: peru con sólo la diferencia de que á esta especle no se le hace incision ó cisura.

\section{Siembra y cullivo,}

Al tienupo do ejecutar el plantio en los cuadros so deberin sacar las plautas de los semilleros y criaderos con buen césped, luego que se les de algun riego, 
se plantan por Octubre 5 Noriembre en eras !lanas $\delta$ en canteros, dejando un pié ó pié 5 medio de distancia: prevalecen bien en los sitios sombrios y frescos I exijen para su cultiro una tierra pastosa 5 beneficiada con mantillo. Son necesarias las labores de primarcra y otoño, para desarraigar las malas yerbas antes que tomen fomento y dañen á las plantas: igualmente se suministrarán frccuentes riegos duranto su florescencia y en tiempo de calor: los plantíos so lenorarán cada tres años; pues aun cuando sigan dando flor por cuatro $\delta$ cinco, algunas plantas lozanas, suelen con todo perderso despues del tcrecr año cle hecho el plantio.

\section{De la Minutisa.}

Las rariedades jardineras do csta flor hermosa, son en sencillas y dobles: las hay blancas, do color do fuogo, de rosa carmesí, encarnada, color de carnc, jaspeada, $y$ disciplinadas con todos los matices; las flores forman una copa hermosa terminal y son oiorosas: florece esta planta por Nrayo, Junio $y$ Julio, y sazona sus semillas por Agosto y Seticmbrc: los tallos dorechos, nudosos, ramosos algo rellosos hácia su basa, lampiños en la parto superior y ercecn hasta pié y medio do altura, las hojas son trabadas, puntiagudas, de consistencia blancla y un rerdo rcluciento.

\section{Siembra y trasplante de criaderos.}

Esta sc hace a mediado do Mrarzo, Abril y Mayo, mas las plantas que se adquieren do la siombra do Marzo lloran conocida rentaja á la más tardía.

So entresacan estas plantas do los scinilloros para

$$
\text { 5. -Jardineria, }
$$


plantar en los criaderos, luego que han crecirlo á la altura de cuatro á cincu dedos, por Junio, Julio y Agosto; so plantan á distancia de tres cuartos de pié, i fin de que se una bien la tierra con la raiz. Se haeen los hoyos eon un plantador delgado para la eolocaeion de la planta, se aprieta bien la raiz para quo quedo segura y cl cogollo fuera de la tierra, erííndose de este modo más lozana.

\section{Del Alelí comun.}

Los eolores de esta flor por lo eomun son blaneos, encarnados, morados y jaspeados, florece desde Mayo hasta Setiembre; su tallo es easi leñoso, rollizo, dereeho, ramoso; ereco de uno á dos piés do alto y vejeta por tres 6 euatro años; las hojas son lanceolado-oblongas, obstusas, blanquecinas, cubiertas de borras, de eonsistencia blandas, revueltas por su ápiee háeia abajo, eon sus márgenes ondeados do ocho á diez dedos de largo y de doee líneas de aneho, son eaedizas, y dejan impresa la señal de su insercion en el tallo; las hojas de los ramos son más pequeñas y estos visten la planta con igualdad y simetría descle su base, y se terminan por sus espigas de flores, muy olorosas.

\section{De el. Alelí griego.}

Los ramilletes de esta flor son numerosos, nacen desde la base de la planta eon arreglo y hermosura $y$ que terminan por el ramo eentral, las flores están dispuestas en espiga floja; floreee por $\Lambda$ bril, Mayo y Junio, los colores mas eomunes son blaneos, encarnados moractos, color de fuego, do earne, de rosa, diseiplinada y abigarrados; las hojas son lanceoladas, lustrosas, lampiñas, carnosas, sentadas y puntiagudas; el tallo es ramoso, casi fruticoso y dura tres años. 


\section{$-67-$ \\ Del Aleli pajizo.}

Estas flores son muy olorosas, termiuales peduncuLadas y están dispuestas á mancra de corimbo, su color es amarillo, rojo, morado, oscuro y abigarrado; florece desde la primavera al otoño; sus tallos frucicosos, rajosos y de poco mas de dos piés de altura, las hojas hnceoladas, puntiagudis, lampiñas de tres dedos de hrgo $y$ de seis de ancho.

Siembra y criadero.

Se siembrau todas las clases de aleb́ á mediados de ¿bril y Mayo, y si se desen que manifiesten su flor desde Hayo hasta. Junio, se verificarán sus siembras por iltimos de $A$ gosto y Sctiembre, que es la época de cembrar el alelí griego. Se acodan y esquejan como se ba esplicado para la minutisa.

\section{Plantío y cultivo.}

Se plantan los alelies en los lugares más risibles del jardin, y euando se desen adormar con todo primor alJuna rriata, se escojen los dobles, se plantan mezclado con otras especies de flor fina se colocan igmalmente en macetas con la idea de adornar los sitios mís useados del jardin; descle mediado de Mar\%o ó Abril, segun lo adelantado 0 atrasado de la estacion, so da principio á los plantíos, se plantan en macetas ó en tierras con las mismas precauciones que fa lie esplicado para has otias plantas.

Los enemigos del alelí son la rosquilla, el alacran y Igunos otros insectos, en particular luego que se ham rasplantado, y antes que pueda arrigar: la oruga des- 
truye igualmente las flores $y$ las hojas, prineipalmente en tiempo de sequedad, $y$ por lo mișmo no hay que desscuidarse con los riegos, esta oruga es pequeña y do color entre rerde y pardusco.

\section{De la Juliana.}

Las flores do esta se hallan colocadas á las extrem; dades de los tallos, son muy olorosas, las hay blancas aznles, carmesíes, encarnadas, jaspeadas y dobles ó scncillas, cuyas rariedades se han logrado por las siembras repetidas de la simiente de ella; florecc por Liayo y Junio: produce sus tallos derechos, rollizos, ramosos, rellosos, de dos piés de aíturi, $J$ muy poblados de hojasanchas, amado-lanceoladas, dentadas y sostenidas por peeíolos cortos y rollizos.

Aunque es el otoño la estacion mas propia para plantar esta flor puede sin embargo diferirse el plantío hasta Febrero y aun Marzo, las plautas de los semilleros se sacarán con cepellon para fícilitar su más pronto arráigu.

Para el cultivo de estil flor convienen los terrenos lijeros de miga, la estromada humedad causa su pér dida $y$ en los terlenos fuertes se malogran, son necesarios riegos moderados luego que se haee el plintio durante la floresencia; asi mismo se darán escardas oportunas y algunos labores de primavera.

\section{Del Arraspique perenne.}

Es planta muy hermosa, muy poblada do ramos laterales que crece á poco más do un pié do altura, las flores dispuestas en forma de corimbo están colocadhs en las extremidades de los tallos, son blancas, mercec 
in singular aprecio por que florece por el otono 5 la primatera, I eon mucha abundancia duranto los meses de Diciembre, Enero T Febrero, en cura éjrocis son apreciables por la escasez de flores. Lns tallos son lenosos, rollizos, algo tortuoso é inclinados por el peso de las flores.

\section{De la Capuchina.}

Pocas plantas reunen ln gracia de la capuchina para a ilornos artificiales, en estos climis es ciertamente sdmirable,, hacen un contraste tan. armonioso sus thojas de color rerde elaro interpuestas con el rirísimo de sus flores, que parece despiden de sí raifigas de fuego, í lo que se agrega de mantenerse tlorido casi todo el año.

\section{De la Fainilla.}

Crece este hiliotropio á dos piés de altưa y produeo sus tallos fructuosos, rollizos, ramosos cubiertos de pelos ásperos, algo tendidos y poblados de muchas hojas alternas a wado-oblongas nerriosas, arrugadas do dos dedos de largo y uno de ancho y sostenidas por peciolos muy cortos y rollizos: sus flores estain dispuestws en espigas enroseadas y ladeadas hácia un lado: forece por el invicrno, unas puerlo cultírarso de mapera que sigan dando flor duranto la mayor parte del aĩo.

De los Jeramos olorosos.

Entre estos las especies rue más abundan -son jernmos de rosa el de olor de limou, y malra de olor, ade- 
mas de estos se cultiran tambien otias muehas espe. eies de jeramos que todos eontribuyen al adorno $y$ her. mosura de los jardines.

Siembras, csquejes, acodos y plantio.

Por Abril y Mrayo es cuando se siembran los jeramos en maeetas ó cajones preparados con tierra lijera, se esparrama la simiente algo clara, se eubre con una capa muy ténua de mantillo cernido quo tenga el grueso eomo de'medio dedo escaso, se riegan eon moderaeion, resguartando los ardor'es del sol. Se esquejan $\mathrm{s}$ aeodan casi todo el año, pero con más rentaja por Na yo, Junio $y$ Julio, 5 en el otoño, regularmente en cuarenta dias suelen estar bien erecilos para trasplantarlos de asiento. Hay algumas espeeies como la malva de olor, que no salen bien por esqueje, y su multiplicacion se rerifica perpetuamente por el acodo. Todas estas espeeies se propagan con la mayor facilidad por medio de sus tallos que se clavan en la tierra y arrailga en joco tiempo: los riegos son muy oportumos para la pronta radicacion y no ménos eontribuye para su logro una situacion sombría $y$ adeeuada.

Las plantas habidas por simiente, acodo ó esqucjo se plantarín en sus eorrespondientes macetas; luego quo hayan crecido lo bastante, y es necesario colocart las en sitios sombrios: se saearán eon sus eepellones sin desinacer, y prevaleecrín mueho mejor por eonservar abrigadas las raices, y sin esperimentar lesiou.

\section{De la Perpétua amarilla.}

Sus flores son eompuestas, numerosas, dispuestas en corimbo terminal, su color es amarillo, hermoso, 
sus tallos se elevan á dos piés de altura, son algo ramosos, blauquecinos, ciuros y leñosos en li paite inferior; lis hojas sentadas, lineales, blanquecinas, rellosas, de tres declos de largo $\mathrm{I}$ de seis líneas de ancho, florece eu Julio, Agosto y Setiembre. Se cortan las flores por Mayo, Junio y Julio poco antes de abrirse del todo, $y$ se pueden conserrar por uuchos anos atadas en manojos ó sueltas, sin que pierdan su color herinoso.

\section{Del Erisantemo de la China ó flor de Roma.}

Florece por Octubre, Noriembre y Dieiembre, s proporciona un escelente adorno en aiuella estacion tan tardia: las flores uacen solitarias, axilares, terminales y pedunculadas, son dobles, do diversos colores y matices, las hay purpuria, uscuro, blaneas, encarnitlas, moradas, amarillis, naranjadas y te $\mathrm{color}^{\text {die rosa: }}$ la flor principal to cada tallo es regularmente mucho mayor que las laterales: el tallo ammil es casi leñoso derecho, rollizo, muy rimoso, de dos ó tres piés do alto y muy poblado de hojas altermas, pinitificadas 0 awandas con senos $y$ hendiduris muy profundas y acerradas, pecioladas, verdes jor arribi, y blanduecinas por ol enrés.

\section{De la Auricula, Oreja de oso ó Montezuma.}

Esta es una planta porenne pequeña quo produco la raiz gruesa, anudada, con varias hebras blancas, las hojas radicales, oblongas, carnosas, the dos dedos do ancho $y$ tres 6 cuatro de largo y do un verde lustroso. Del centro de estas hojas so eleva un tallo eilindrico de seis ú ocho pulgadas de largo, que terminam por 
'nn intolucro de muchas hojuelas pequeñas, de cuyos sobacos śalen los pedúculos delgados J cada uno sostienc una flor de mucha fragancia y de dirorsos colores vivos y hermosos.

Sc siembra de semilla por Narzo y Abril, florece de Junio hasta Octubre. Se mnltiplica tambion por hijos que brotan de sus raices.

\section{MIadamas.}

Sc propaga de semilla que nace desde cl mes de Marzo hasta Obtubre, ląs plantas qne nacen on los primcros meses, erecen con mas lozanía y prodnecn más hermosas fiores; las hay do flores sencillas y mny monudás, cstas últimas ticnen más mérito, por los numerosos pétalos qne adornan cada flor, las hay blancas, rosadas, púrpura, moradas, flor de romcro, matizadas de blanco y púmpura, de blanco $y$ rosado $\mathrm{y}$ de blanco y morado; requiercn terreno abonado $\mathrm{y}$ regular riego, cnando empiczan á florceer que es á los dos meses de nacidas, convicne aporcarlas que consiste en renovar la ticrra arredcdor de su tronco, sin lastimar las raices y arrimar sobrc ellas ticrra, csto dá gran vigor á la planta $\mathrm{y}$ sus flores aumentan cn tamaño y belleza.

\section{MIanto de la Vírgen.}

Lo hay con hojas atcreiopeladas color do púlpura, púrpura con ribetos verdes; verde snbido con manchas moradas, verde claro con pintas moradas y morado enrojecido; los tallos echan raices fácilmentc, requicren terreno abonado $\mathrm{y}$ mncho riego, su tronco y hojas si sc csprimen, producen una tintura color violeta, hermosa. 


\section{ILoya.}

La hay blanca, amarilla, rosadia y morada, so siembran de hijos quo nacen al pié, es flor mny ristosa, requicre terreno abonido.

\section{Derbena.}

Planta rastrera, sus guias se van arraiganclo, las que se cortan $y$ arrancan con lits raiecs y tiorral unitas i ellas $I$ se trasplantan en macetas colocándolas it la sombra 5 regíndolas diariamente por lia tarde, clo esto modo se reprodncen fícilmente, floreco mucho 5 las hay blaneas, rosadas, moradas y rojas, adorna mucho los jardines.

Berdolaga francesa.

In hay de dos clasos, pero la mís apreciada pari adorno en los jardines, os la quo tiene las hojis do un rerde claro eon manchas blancas, so propagi de semilla 5 para más violencia de gajos, roquieren riego eonstantes.

\section{SECCIOIN QUINTA.}

DE LIS PLATIS PEREXES QTE SJRYEX PIRI ADORNAR LOS JLRDENES

\section{De la minavera.}

Se prefieron las primareris cuyos bohordos son gruesos, y su flores que tengan dos 6 tres colores bion matizados, como el morado, aterciopelato, negro, pur- 
púreo, uaranjado, blanco, rosado y rerde; estas flores deben ser anchas, dispnestas en figura de rueda; el tubo de la corola es corto, la boca amarilla y las divisiones del borde bieu variadas con colores brillantes, colocados con simetria; es planta rivaz con numerosas hojas radicales, oblongas rngosas dentadas, nerviosas, redondas en sus estremidades y angostalas hácia su base, de cuatro á seis derlos de largo y de uno á dos de aucho, verdes por arriba $y$ amarillentas por el reves: en el centro de la plautia nacen varios pedundúculos radicales, tan largos como las hojas, $\mathrm{y}$ terminados por una sola flor. Se siembri de seruillit ó hijos por Majo y Junio.

De la violeta.

Las flores de esta plauta son blaueas, riolado y jaspeado, tienen nua fiagancia esquisita, y floreeen por Enero, Febrero y Nar\%, se diferencian en sencillas y dobles, cultirándose cou preferencia las íltimas por ser la flor graude y hcrmosa y se desechan las sencillas: las flores son solitarias, cabizbajas $\mathrm{y}$ están sosteniclas por pedúculos radicales de unos cnatro dedos de largo, y con dos bractens opuestas aleznadas: la raiz es pereme, rastrera, blanqueciua y prodnce muchos rennevos: las hojas son radicales, pecioladas, acorazomadas, dentadas, lampiñas, de un rerde lustroso por la parte de arriba, $\mathrm{y}$ de un en!or mas claro y algo vellosas por el revés. Se siembra descle Marzo hasta $\Lambda$ bril; la sombra de los árboles les finrorece.

De la Margarila.

Es planta de tallos bajos que adorma maravillosamente la primavera, eu euya época manifiesta sus her- 
mosas 5 abundantes flores blancas, cnearnadas, con fajas blaneas, encarnadas $y$ blaneas y rerte $\mathrm{cn}$ ol ecutro, son prolíferas; que pululan de la flor prineipal otras mas pequcñas, sostcnidas por pieceiellos parciales: produce las hojas rudieales, cspontuladis, los pedúnculos rellosos, maeizos en su base y huecos en la parte superior, de cuatro í einco dedos de alto y terminados por una flor compnesta.

Produee muchos hijos de sus raiees los que para su multiplicacion so. siembran por el otoño.

\section{De la piramidal.}

Es una do 'las plautas más vistosas del jartin, sus flores son numcrosísimas, blancas ó izulcs, cimpanudas, y coloeadias al rededor clo los tallos á manerir de pilámide; la raiz es grucsi y lcchosa, do ella meen tres, cuatro ó más tallos derechos do mas do cineo piés, entre estos cl centril supcrin siempro en altura í los demás, y manifiesta su flor con antieipacion á los pcqucños; las hojas radicales son oblongis, lampiñas, festonadas de un verito listroso, y migores (jue las thel tallo. Se siembra do semilla por Febrero y Mirzo:

\section{De la pajarilla ó manto real.}

Las flores uncen en la extremidad de los tallos, son numcrosis, eabizhajas los eolores mas commessom $\mathrm{cl}$ eneninado, rosa, fuego, azulado, moridlo, blanco y of jaspeado; son sencillis y dobles; es planta peremne; sus tallos erceon á tres piés de alturil, y son dorechos J ramosos, las hojas rudicales son grantes pecioladas, tritcrnadas eon hojuelas redondeadas, festoneadas, do 


\section{$-76-$}

un rerde oseuro en la parte superior, y amarillenta por el revés, las del "tallo soil pequeñas, $\bar{y}$ las superiores sentadas, ternadas 6 cou tres divisiones y rarias vecos enteras; duran por espaeio de muehos años, produciendo flor, su major vigor lo adquieren al tercer año de scmbradas; y empiezan á degenerar pasado los seis años. Se siembia de semilla por primavelia.

\section{De la vara de oro.}

Esta flor americana, sc cultiva para adorno de los jardiues y producen sus tallos muy poblados de hojas, de tres á oeho piés de altura y terminados por sus grandes panojas de flores de eolor amarillo dorado que las manifiesta por Agosto, Setiembre y Oetubrc.

Se siembra de semilla por MIarzo.

\section{De la viuda ó escaviosa.}

Los colores más eomunes de esta flor es el morado, eneal"nado y blaneo, eada flor tiene dos cálices adherentes: los tallos son rollizos, nudosos, ramosos y ereeen poco mas de pié y medio, las hojas radieales son scncillas, festonadas, ovales y angostas hácia cl peeiolo, y las del tallo, opuestas, pinadas 6 impares $y$ so eomponen de uueve hasta trece hojuelas oblongas, tanto mas grandes, cuanto mas inmediatas á la impar ó última lojuela, los ramos naeen del sobaeo de las hojas, florece por Julio y Agosto, se siembra de semilla jor Marzo.

\section{Del Don Diego de noche.}

Florece esta planta desde Jumio hasta principios de 
invierno, se abren sus flores despues del sol puesto, permaneciendo hasta por la mañana que ruolro í cerrarse, á ménos que esté el dia uublacio que entónces se mantiene abierta: las numerosis flores que produce esta pla,ata, los abundantes ramos, sns preciosos colores blancos 5 encaruados, color de oro 5 el jaspento, la espesuma de sus hojas anchas $y$ el bilsimico olor tan agradable, la hacen de un mérito estimado. La raiz que produce es aguzada, camosi, gruesi s le in pió de largo; el tallo es herbaseo, lereclio, nindoso, con linmos horqnillados y se eleva á dos ó tres piés do altura: las hojas opuestas son auradas y terminadas en punta. Esta planta es originaria del Perú, $Y$ os reputida por la rerdadera jalapa. So siembra do semilla por Fobroro y Marzo.

\section{De la malva real y rosa altea.}

En el color de las fiores se advierte gran rariedad; las liay blancas, color do rosa, de fllogo, do caña, euearuadas, moradas y negruscas ó juspeadis, continúa snecsirnmente en flor por espacio de dos meses lesde Julio en adelinte; los tallos suben a imas do ocho pliss de altura, gmesos, derechos y desto su mitad hácii arriba, se viste hermosamento de mnchísimas flores dobles ó sencillas colocadas en furma de espign: las lojas grandes, alteruas, acorazonadas, jugosas y festomadas, se roprodnee de semilla quo so siembra por Marzo.

De la Pconía.

Esta es ma flor hcrmosa de color de fuego, le rosa o blanca, de ocho á diez dedos de diámetro se cultivau 
solamente las dobles, fforecen por Majo $y$ Junio; los tallos son ramosos de uno ó dos piés de alto y adornado de muchas hojas graudes, alternas, pinados, con sus hojuclas sencillas en varias tiras; de manera que parecen scr dos, tres 6 cuatro veces peinadas, cada tallo se termina por una sola flor, se siembra de semilla y de hijos que brotan de las raices.

\section{De la Dalia.}

La dalia proporciona un adorno muy especial on los jardines durante la estacion de verano y otoño por la elevacion y frondosidad de sus tallos y ramos muy poblados de hojas grandes; lustrosns $\mathrm{y}$ variadas, por la diversidad de sus tintes y por el tamaño, figura y color brillante de sus flores que forman un contraste agradable y hermoso: florecen por Agosto, Setiembre, Ocbre y Novicmbre, las raices son tnberosas y se componen de un conjunto de scis ú ocho tubéreulos globosos, oblongos, grandes, carnosos, macizos de un color ceniciento oscuro en la parte exterior y blancos al interior: tres son las especies que sc conocen por el color de sus rayos femeninos, siendo de color de rosa pálido en la clália rosa; de color de grana en la collinea; y de púrpura oscuro en la dalia pinnata.

Un célebre jardinero, ha comunicado recientemente ála academia de ciencias de París, que regando con agua tibia al pié de estas plantas, adquiere sul flor que es inodora, un delicioso perfume semejante al de la rosa de Alejandría.

$$
\text { Siembra, plantio y cultivo. }
$$

So siembran las semillas de estas plantas por Abril 
en uนa mezcla lijera y sustauciosa como la que conrieve a casi tudas las plamtis delicadis, I’so cubren con un dedo he mantillo mur cerviso y pasado; sueleu empezar a jerminar á las tres somanis do sembradas: on el primer aũo creceu de tres á clatro piés cie altman $y$ rejetan muy endeblewente, produciendo pocas hojas $\checkmark$ Horece por el otoño, sigue ammeutando pol' graclos su produccion hasta los tres aũos ó cuatro que es cuando llega al mayor grado de perteccion y heruosura, couriene regarla á menudo durante la estacion calorosa y tener cuidado de arrancar todas las yerbas extrañas.

Todas estas plantas se multiplican my fícilmento por la division de sus tubérculos, enya operacion se hace despues de haberse secado sus tallos, y ántes de que empiecen á brotar otros nueros en la primarera; los tubéreulos que se separen de las raices principales para propagar la planta, serín de los más crecilos, pues cuando son muy pequenias se suelen perder muy fícilmente, se plantarán á scis ú ocho delos de profundidad en terrenos sustanciosos y fértiles.

Poco 'antes de empezar í brotar las plantas por la primavera, se darí un labor con ol almocafte para deshacer la costra, almecar la ticr'a y facilitar pol este medio la rejetacion $y$ que nada les impicla su libre sitlida, $y$ al unismo tiempo sc benéficiari el terreun con mantillo: so nsarín algmos riegros eseasos c'll lat primavera, despues que hayan empezado il butar las plantais $\mathrm{y}$ se repetirin segun la estacion.

\section{SECCION SESTA.}

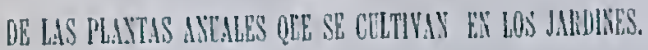

De la Flor Actonis.

Dos son, las especies naturales de esta flor, la del 
otoño I la del verano, son muy parecidas 5 so distingucn solamente en los firutos que son cilíndricos en la de otoño y amado en las de remno, por el cultiro se han obtenido rariedades de flores grandes muy apreeiables por su color eneendido de fuego: de simiente cle estas se logran flores perfectamcnte dobles, incapaces de producir semillas y por lo tanto difíciles do multiplicarse por ser plantis quo perceen todos los años, se reproduee do semilla como las anteriores.

\section{De la Espuela de Caballero.}

Dos plantas dirersas so cultivan conl este nombre, la primera que es hermosa, crece á la altura de tres 6 cuatro piés y produco el tallo rollizo, derccho, ramoso y con muchas hojas alternas, el tallo y los ramos se terminan por sus espigas de flores dercchas, de quincc á veinto dedos de largo. Las muchas varicdades se distinguen por sus flores soneillas, semidobles $\mathrm{y}$ dobles; de color blanco, morado, azul, enearnado, de rosa, de carne jaspeado. La segunda que es la enana es la variedad más preciosa de esta especio por cuanto produce una sóla espiga muy guarnecida de flores que hace un maravilloso efecto, so reproduce de semilla que se siembra en Febrero o Abril.

\section{De la adlormidera y de la amapola.}

Las flores son solitarias, terminales, se dividc en seneilla y roblc, do color blanca, encarnada, morada, y otros muchos, su tallo es derecho, lampiño, ramoso en la parte superior, dę tres á cuatro piés y guarnecido de hojas alternas, cue abrazan el tallo de color rerde amarillento, rccortadas y dentadas con desigual- 
dad; florece esta planta por los meses do Mrayo, Junio
y Juljo.

La amapola comun ha dado por medio del cultiro, hermosas variedades dobles y sencillas, las principales son las moradas, carmesícs, cncarnadas, blancis, listadas, jaspeadas $\mathrm{r}$ con franjas plateadas, se siembra la semilla como la anterior.

\section{De la Flor de eupido.}

Esta hermosísima flor do color azul ó morada es plauta bienal que couserva su regetacion á rcees dos 6 tres años, por' lo regular perece luego que se hau marchitado sus flores, cs natural cle Espaũa, sus tallos crecen á dos piés, delgados y cubiertos do borra, las hojas casi lauccoladas, estrechas; vellosas, blanquecinas, $y$ con dos 6 tres diolites eu cada una de sus márgenes, las flores están colocadas cu panojas termiuales; la rariedad doble de csta plauta quo so ha logrado por el cultivo, es la quo so cuida cn los jardiuos, su siembra do similla como Ja anterior.

\section{De el espejo de Vénus.}

Crecc esta planta á un pié do altura, produce sus tallos delgados, lamosos, y algo tendidos, las hojas dentadas oblongas, las flores axilinres, solitarias, derechas, do color cncal'nadọ que tira á morado y llovadas por pedúculos usuy largos, la corola es cn forma do rueda y se halla prótundameuto dividida en cinco divisiones avadas, flowece deslo Mayo hasta Seticmbre; couricue mejor para las macotas quo para sumbrar en terrenos; se cuida y siembra lo mismo quo la anterior. 
De la flor de los pensamientos. aleli de Mahon y arañuela.

Esta planta anual, cuyas flores son muy abundantes y hermosas, varian ou su color $y$ tamaūo, muchas veces las producen, amarillas, otras blaucas ó azuladas; pero lo mas regular es hallarlas hermosamente variadas, teuiendo los dos pétalos superiores amarillos con uña mancha de color de púrpura en cada uno; liss dos de eu medio de un blanco amarillento; ' y el inferior de púrpura oscuro y como aterciopelado, duran en flor desdo últimos do Harzo hasta Junio, una vez sembrada se reproducen auualmente por la simiente madura que desprende on su circunferencia sin necesidad de cuidados de ninguna especio.

De la misma clase sou el alelí de Nahon y la Arañuela, thores muy preciosas y de colores brillantes, con una fragancia muy agradable; pero la mis apreciable de estas plantas es el que uua voz sembradas se leproducén cllas solas sir necesidad de cuidados ni cultivo; $y$ antes al contrario es necesario arrancarlas' por su mucha abundản cia s pari que crezcan con mas vigory lozanía.

-1 Del carraspique ó pinito de flor.

Sus flores son blancas sin mezcla de otro colur peru con el cultivo se hau loglado algunas variedades de color do carno y moradas, es plianta do mediaua altura que floreco por Marzo y Abril, y en este cliua tambien por el otoño, las zumerosas fiores con que se hermoseru los tallos y ramos, unas reces dispuestas en parasoles espesos y otras remidas en coriubos apretados, formall una vista encantadora y agradable. 
Siembra y cultivo.

Se siembran estas $\mathrm{y}$ las anteriores por últimos do Julio y eu Agosto reguardándolas de los ardores del sol y regándolas oportunamente.

\section{De la Mararilla ó suspiros.}

Florece esta flor la mayor parte ucl año, por el cultiro sc han logrado algunas hermosas variedades dc flor doble de color de Daranjas carmesies y abigarradas; es una planta pcqueña, que ticne cl tallo grueso muy ramoso y afelpado, las hojas amarillentas, las superiores laneeoladas, awado obtusas: las floces cstín sostenidas por pedtículos largos y desnudos y nacen en la estremidad de los ramos, su raizes larga y gruesa, oscura por fuera y blanca por dentro, estas se cortan cn ruedas, so eusartan en un hilo $y$ se dejan sccar í la sombra $y$ se sustitupe á la jalapa, pues tieue las mismas propicdades, luego que sc han pasado y mar. chitado los semiflóculos se abren los ch́lices del centro y mauiticstán la scmilla que se desprenden naturalmente con lo que dá lugar á una multipheacion estraordinaria, que es nccesario arrancar las mis de cllas.

\section{Del guisante oloroso.}

Plantia graciosa por el color y olor agradable de sus flores, sus tallos son augulosos, ramosa y vellosos, sus hojas se componen de dos hojuelas awado oblongas de más de una prigada, algo pelosas, los pedúnculos axilaves, calla uno con dos grandes flores que ticno el 
cstandarte de color de rosa y los demás pétalos blancos, ó de púrpura oscuro y las alas y quilla azules: t!orece desde DIajo hasta Agosto y es originaria de la India. Se siembra de asíento yor Octubro y Noviembre $\sigma$ por Febrcro y Marzo, poniéndoles sus enrames para que cnreden sus tallos sarmentosos, ó se ponen al pié de algun árbol para que vistan hermosamente su tronco: csta cs una de las principales flores que se destinan para el adorno de un jardin.

\section{Don Diego de dia tricolor.}

Esta planta tiene la propiedad de abrir sus hermosasflores campanudas durante $\theta 1$ dia, y eerrarlas do nocbe y aun en dias nublados; florece desde Mayo hasta Agosto, sus flores son muy abundantes $y$ vistusas y están adornadas cou tres colores que son cl azul, blanco $y$ amarillo, sc siembra de asiento por Marzo y Abril, y prevalcce en lr's sitios frescos $y$ orjllas de los cer. cados.

\section{De la cuarcnlena ó encanto.}

Tienen estas plantas tnnta analogia con los alelíes que dificilmente se distinguen de ellos á no scr por sus tallos herbáceos y anuales, y del mismo modo que aquellos, varjau estas con las flores sencillas, somidoblcs dobles, blancas, encarnadas, de carne, de rosa, de fuego, moradas, azotidas y jaspeadas, crecen los tallos á dos piés de altura, son rollizos, ramosos y guarnecidos con hojas lanceoladas, vellosas, son unas veces alteruas, otras opuestas y muchas veces nacen de tres en tres; las flores terminin los ramos nacen en espiga floja, son olorosas y florecen á los cuarcita 
dias de hanerse sembrado por la primarera, quo es el tiempo en qui se haee.

So reprodueo de semilla,

\section{De la nicaragua ó Iltrame lindo.}

Esta planta an ual es originaria del Perú, y sn •tllti. ra en tollos los jardines por la sobresaliente hormusura de sus flores; es planta luuy vistosib $y$ forma un poblado do muebos ramos y hojas carmosas, cuyo eolor verdoso interpuesto eon la brillantéz $y$ diversidad de eolores eon que pintó la uaturaleza sus flores, einsa maravilla; so distingueu en sencillas y dobles, blaneas, eolor earue, de rosa, de fuego, moradas, amarillas y jaspeadas do diversos matiees: el tallo es ramoso, rollizo, lampiño $\Sigma$ algo earnoso; las hojas alternas, oblongas $y$ festoneadas, $y$ las flores pedueuladas $y$ aesilares, algunas reees solitarias, pero mas eomunmente de dos en dos, floreeo desdo Junio liasta Setiembre, so siombra de semilla desilo Febrero hasta Nayo.

\section{Del papagallo tricolor.}

El mérito de esta planta eonsiste en lia varjedad quo prosenta sus hermosas hojas manehadas do enearnado on su base, de amarillo en el medio, $y$ do rerdo en sus estremidades, y algunas véees tambiea toman las lıojas jóvenes, un eolor púrpura muy singular. Esta planta, indigena de la Indiia, erkeo á la al tura de dos 6 tros piés, I su tallo es dereeho, laınpiño, ramoso y muy poblado de hojas alteruas, lanecoladas, ovaladas y po. eioladas: las flores masenlinas y femeninas maeon do los sobacos de las últimas hojas, y es donde á su tiem- . po so recoge la semilla. 
Del Mloco der Pavo.

Esta plauta originaria del Perú, crece hasta cuatre pies de altura, y preduce los rames grucses, on cuyas estremidades cuelgau las espigas de la flor masculiua, que tienen a veces un jié de largo, de forma cilíndrica, purpúreas y aterciepeladas la centrapesicion quo presenta el perte rare de la planta $y$ el coler rerdo clare de sus hejas, con el contraste de sus espigas celgantes censtitugen un adolue bien singular en les jardines por etoñe.

De la cresta dle gallo.

Esta planta es apreciable por sus uumerosas flores terminales: dispuesta en cspiga apretada, cemprimida y come aterciopelada que repres enta la figura de una. uresta de gallo: la variedarl de celeres que sobresale en esta plauta, es la cáusa de que se censidere ceme une de les principales ádernes en los jardines por el verano. Los celores más cemunes sen el carmesí, el amarille $\mathrm{y}$ el blance, cen diversidad de tintes, notíndose en inuchas fleres que adquieren un jaspeade $\delta$ Latizado, que real\%a más el mérite de esta planta y que se mantieno cen fler dosde el mes de Julie hasta Setiembre.

\section{De la immortal ó perpétua ó morada.}

Sen tres las variedades cultivadas de estas plautas: la primera produce las fleres coler de pírpura; la segunda, colur de pérla 6 nácar y la tercera jaspeada: sus talles crecon cle uno á dos piés de alte, son, dere- 
chos, artieulados I ramosos, las hojas opuestas, sentidas, oraladas, Ianeeoladas 5 rellosas; las flores nacen reunidas en cabezas globosas. Con motiro do carcere de jugo las flores, $y$ hallurse secas al theto durate su rejetieion se mantiene cun su brillo y en buena eonservacion por muchos añs con tal que se corten y aten los manojus en tiempo seco, colgíndolos lespues al aire, por lo que sirren para adolua los altares y haeer coronas, floreco descle Junio hasta Oetubre, so siembra de semilla yor lieirzo.

\section{De la jlor alch canario.}

La flor del eanario, así llamada por ol color amari110 do sus flores, quo son más pequeñas quo las do la eapuehina: es planta dolienda originaria del Pertútlorece casi todo el año, los tallos suu sarmentosos, jugosos, y so estiender por el snolo euando no encuentra apojo para sostenerse, las hojas altaneras, abroquoladas, euehidas en einco tiras obtusas, amarillontas por el revés y más eortas que los peeiolos, lo euyo so. baeo naeeu los pedúneulos aesilares, muy largos y delgados que sostienen una sola flor amarilia, tloreco por Febrero y Marzo y so siembra do semilla do Jumio has. ta Agosto.

\section{De la estraña ó reina Jargavita.}

Sus anchas, mumerosas $\mathrm{y}$ hermosas tlores, adornan maravillosamento por su estrañeza y variedad los jardines: las hay sencillas, dobles y semidobles, siendo las dobles do mayor apreeio; sus coloros son rários, las hay moradas, violeta, azules, oncarnadis, blaneas, jispeadas y abigarradas: el tallo do osta preelosn plan- 


\section{- 88 -.}

ta creco hasta dos pies do altura, os rollizo, velloso; muy ramoso y guarnecido do muchas hojas alteruas, awaklas, lampiñas, casi tan largas como anchas puutiagudas, con dientes desiguales, pestañosos en sus márgenes y sostenidas por peciolos gruesos y acanalados; produce las flores terminales, solitarias, $y$ do cuatro ó cinco dedos de diámetro, se siembra de semilla desde Agosto hasta Octubre, 1 lorece por Junio y julio.

\section{De la damasquina ó copete.}

Florcee esta planta abundantemente por el verano y otoño, $y$ agiacian,mucho sus flores matizadas de co lor naraujado y morado, so tienen por más perfectas las flores que adquiercn un color de púrpura oscuro mezclado con el amarillo, $J$ ostos piés son los que so destinan para la recoleccion do simientes siempre que sean dobles; es planta anual y uriginaria de Méjico, su tallo crece hasta dos piés, es derecho, rollizo, herbacco y muy ramoso, las hojas pinidas con impar, con las hojuclas lanceoladas y dentadas; produce las flores solitarias, acsilares, terminales y sostenidas por pedúculos más gruesos y huecos en la parte iımediata ¿́la flor.

\section{Del mirabel ó pinito.}

Esta planta anual que se cultiva mucho por la hermosura quo presentan sus tallos y hojas verdes, y por su mucha duracion en la estacion del veranu: se siembra en Febrero y Marzo, de asiento ó se trasplantan cuando tieno do tres á seis cledos de alto, requieren riegos frecuentes. 


\section{LISTA ALFABETICA}

de otras plantas que se pueden cultizar en los jardines de Cuba, empleándose con ellas los métodos aconsejados para todas las demás plantas de que se ha hecho mencion en esta obra.

A.

Agenjo.

Acacia.

Amapola.

Acanto.

Amaranto.

Adclfa.

Achicoria.

Amigalida.

Aguililla.

Azapan.

$\Lambda$ brojo.

Adormidera.

Amaro.

Amarilis,

Arrayan.

Ambarina.
Alhuzema.

Aguiualdos.

Amesquines.

Aroma.

B.

Bella Rita.

Batata.

Bo-pluta.

Brujas.

Bonasí.

Babiana.

Bácara.

Bogola.

Borraja.

Bleo.

Berro. 
c.

Cunde-amor.

Coledonia.

Citronela. .

Ciprés.

Camelia.

Col-chicó.

Coronill.

Crisomo.

Coronado.

Caracolillo.

Cordovan.

Cagigal.

Chambergo.

Clavellina.

Cinco llagaś.

Cina mono.

Copeta.

Cambustela.

Cenitúuro.

Cardo santo.

Culebra calabaza.

Chamico moñudo.

D. .

Damasco.

Diente de perro. Diamela. i.

Eglatina.

Eliotropo.

Limbeleso.

Escabiosa.

Espino.

Espejo de venus.

Estraña rosa.

Encanto.

Escoba amarga.

Estropajo.

F.

Flor de Lis.

Id. de San Pedro.

Id. de Andruis.

Id. de Cupido.

Id, de la Pasion.

Id. do Altea.

Id. de agua.

Id. del pato.

Id. romana.

Francesillas.

Falsa acacia.

Flor de la blanca mariposa.

G.

Gunoamayas. 
Guacamaya francesa. Galan do nocize. Id. do dia.

Guerters.

Granadino.

Globo de oro.

Gujats.

Güirito de olor.

Guaco.

Gui-emoil.

II.

Hepática.

Hermosa Raquol.

Higuereta.

I.

Iris.

Inmortal.

J.

Jacinto.

Jazmin de Italia.

Id. del Cabo.

Id. amarillo.

Junquillo.

Jeringuilla.

L.

Laurol.
Lilia.

Iaurol rosa.

Lípulo.

Lirio sanjuanero.

Limoneillo,

I1.

IIuraila.

Mralangas de color.

Mirabel.

Margaritir.

Malra thé.

Nalva rosa.

Maxidre soly̨i.

Milito.

Mlirto rosa.

Moral.

Museo.

Maraũuela.

Mírame lindo.

Mastucrzo.

Mranto Real.

Minutisa.

Mratricaria.

Manzanilla.

Marisquenot.

T.

Nareiso.

Nolumbio.

Nicaragua. 
Nardo.

o.

Olivo.

Ortiga.

Oreja de oso.

Id. de oro.

ojo de poeta. orégano.

P.

Pasionaria.

Perpétua.

Primavera:

Pensamiento

Platanillo de Cuba.

Panetela.

Painporsino.

Pajarilla.

J.omarrosa.

Paraiso.

Pardos.

Piramidal.

Pino enano.

Pata de gallina.

Piñon.

Pitajaya.

R.

Resedá.
Romerillo.

Retama.

Renuecio.

Rabo de zorra.

Rabo del diablo.

Rosa francesa.

s.

Siempre-viva.

Sensitiva:

Serpor.

Serval.

San Diego.

Solitaria.

Sangre.de Adonis, Salta-Perico.

T.

Tibo.

Trinitaria.

Tuberosa.

Terciopelo.

Tararáco.

Tuna blanca.

v.

Varita de San Jose.

Vara de Araon.

Villorita.

Vellocina.

Vainilla. 
Fellocino.

Terbena cimarrona. Vegonia.

$-93-$

\section{Y.}

Yedra.

Yerba doncella.

Yecolto pina.

Yerba angélica.

Id de Sau Juau.

Id, gigante.

Id. mora.

Id, piojera.
Yuyo.

Yerba zamarrilla.

Yauten.

Yerba de la saugre.

Ycrba de Garro:

z.

Zarza-rosa

Zarapico.

Zapaten del Obispo.

Labira.

Zamarrilla azul.

Zíbila ó Zádida. 


\section{INDICE.}

Páginas.

Las flor'es....................... 3

Importancia del abono y del mantillo...... 4

Cultivo de los rosales y rariedades........ 6

Multiplicacion por acodo $\delta$ rama......... 10

Mrétodos para injertar las plantas......... 11

De la lila.......................... 14

De la celinda....................... 15

Ccl resedan....................... 15

De la hortensia..................... 16

La retama de flor................... Is

Rosa quclders....................... 19

De la falsa Acacia.................. 20

Del arrayáu ó murta................. 21

Plantas' volubles y trepadoras........... 22

Ycrbas y plantas aromáticas medicinales.... 23

Dc las cebollas y bulbos de flor........... 27

Anémone......................... $\quad 27$

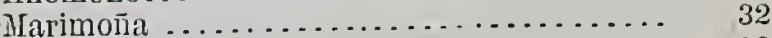

Jacinto ......................... 33

Del Tulipan....................... $\quad 35$

'Tulipanes para el tocador.............. . 38

De la Pritilaria...................... 38

Del Natciso........................ $\quad 39$

Vara de José ó uardo oloroso............. 40

Do la azuccnn $y$ el matagon............ 41

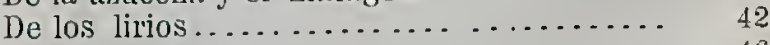

Del pomporsino................... 46

Del azafran ...................... 47 
PIGNAS.

Violeta diente dé perro .............. 49

Campanilla de verano............... 50

Flor de lis......................... 51

Hermosa Raquel................... 52

Del clavel y clarellina................ 53

Esquejar los claveles................ 57

Acodar los id ....................... 59

Enemigos de los claveles.............. 62

Clavel coronado.................. 6

De la minutisa................... 65

Alelí comun .................... 66

Id. griego ...................... 66

Id. pajizo...................... 67

De la Juliana........ . . ......... 68

Del arraspique.................... 68

De la capuchina..................... $\quad 69$

De la rainilla........................ 69

Do los jeramos.................... $\quad 69$

Perpetua amarilla $\ldots \ldots \ldots \ldots \ldots \ldots \ldots \ldots . \quad 70$

Flor de Roma.................... 71

De lit auricula..................... 泣

Madamas....................... 72

Manto de li Virgen.................. 72

Iloya......................... 73

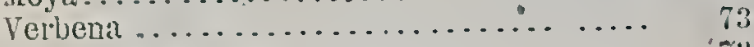

Verdolaga francesa.................. 73

Primavera..................... 73

Violeta........................ 74

Vavyaritil......................

Piramidal .........................

Mranto Real..................... 75

Vara de oro....................... 76

Viuda ó oscabiosa................. 76 
Pígnas.

Don Diego de noehe................ 76

Malva Real......................... $\quad 77$

Peonia............................... 77

De la Dalia. ....................... $\quad 78$

De la flor de $A$ donis ................... $\quad 79$

De la espuela de caballero............... s. so so

Do la adormidera $\mathrm{y}$ amapola ............... s so so so

Flor de Cupido....................... 82

Espejo de Vénus.................... 82

Pinito flor......................... 83

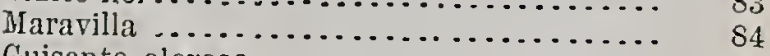

Guisante oloroso....................... 84

Diego de dia......................... 85

Cuarentena $o ́$ encanto...................

Míramo lindo ....................... 86

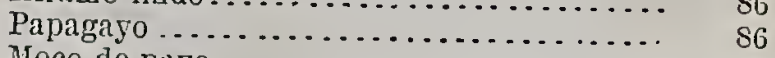

Moco de pavo............................. 87

Cresta de gallo ..........................

Inmortal $\delta$ perpetua....................... $\quad \delta 7$

Flor de Canario....................... 88

Reina Arargarita..................... ss

Damasquina.......................... $\quad 89$

Miravel $\delta$ pinito....................... $\quad 89$

Lista de otras plantas que pueden eultjvarse. 


. 


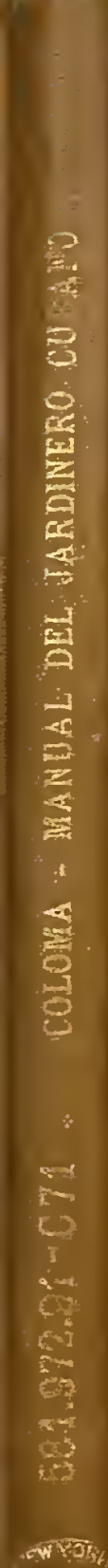
othitiof 4ape 